\title{
Near-surface and columnar measurements with a micro pulse lidar of atmospheric pollen in Barcelona, Spain
}

\author{
Michaël Sicard $^{1,2}$, Rebeca Izquierdo ${ }^{3}$, Marta Alarcón ${ }^{3}$, Jordina Belmonte ${ }^{4,5}$, Adolfo Comerón ${ }^{1}$, and \\ José Maria Baldasano ${ }^{6,7}$ \\ ${ }^{1}$ Remote Sensing Laboratory, Universitat Politècnica de Catalunya, Barcelona, Spain \\ ${ }^{2}$ Ciències i Tecnologies de l'Espai - Centre de Recerca de l'Aeronàutica i de l'Espai/Institut d'Estudis Espacials de Catalunya \\ (CTE-CRAE/IEEC), Universitat Politècnica de Catalunya, Barcelona, Spain \\ ${ }^{3}$ Departament de Física, Universitat Politècnica de Catalunya (UPC), c/Urgell 187, 08036 Barcelona, Spain \\ ${ }^{4}$ Departament de Biologia Animal, Biologia Vegetal i Ecologia, Universitat Autònoma de Barcelona (UAB). Edifici C, \\ 08193 Bellaterra, Spain \\ ${ }^{5}$ Institut de Ciencia i Tecnología Ambientals (ICTA), Universitat Autònoma de Barcelona (UAB), Edifici Z, \\ 08193 Bellaterra, Spain \\ ${ }^{6}$ Earth Sciences Department, Barcelona Supercomputing Center - Centro Nacional de Supercomputación, Barcelona, Spain \\ ${ }^{7}$ Environmental Modeling Laboratory, Technical University of Catalonia, Barcelona, Spain
}

Correspondence to: Michäl Sicard (msicard@tsc.upc.edu)

Received: 11 March 2016 - Published in Atmos. Chem. Phys. Discuss.: 16 March 2016

Revised: 18 May 2016 - Accepted: 21 May 2016 - Published: 6 June 2016

\begin{abstract}
We present for the first time continuous hourly measurements of pollen near-surface concentration and lidarderived profiles of particle backscatter coefficients and of volume and particle depolarization ratios during a 5-day pollination event observed in Barcelona, Spain, between 27 and 31 March 2015. Daily average concentrations ranged from 1082 to 2830 pollen $\mathrm{m}^{-3}$. Platanus and Pinus pollen types represented together more than $80 \%$ of the total pollen. Maximum hourly pollen concentrations of 4700 and $1200 \mathrm{~m}^{-3}$ were found for Platanus and Pinus, respectively. Every day a clear diurnal cycle caused by the vertical transport of the airborne pollen was visible on the lidar-derived profiles with maxima usually reached between 12:00 and 15:00 UT. A method based on the lidar polarization capabilities was used to retrieve the contribution of the pollen to the total aerosol optical depth (AOD). On average the diurnal (09:0017:00 UT) pollen AOD was 0.05, which represented $29 \%$ of the total AOD. Maximum values of the pollen AOD and its contribution to the total AOD reached 0.12 and $78 \%$, respectively. The diurnal means of the volume and particle depolarization ratios in the pollen plume were 0.08 and 0.14 , with hourly maxima of 0.18 and 0.33 , respectively. The diurnal mean of the height of the pollen plume was found at $1.24 \mathrm{~km}$
\end{abstract}

with maxima varying in the range of $1.47-1.78 \mathrm{~km}$. A correlation study is performed (1) between the depolarization ratios and the pollen near-surface concentration to evaluate the ability of the former parameter to monitor pollen release and (2) between the depolarization ratios as well as pollen AOD and surface downward solar fluxes, which cause the atmospheric turbulences responsible for the particle vertical motion, to examine the dependency of the depolarization ratios and the pollen AOD upon solar fluxes. For the volume depolarization ratio the first correlation study yields to correlation coefficients ranging $0.00-0.81$ and the second to correlation coefficients ranging $0.49-0.86$.

\section{Introduction}

Pollen is the male gametophyte of seed plants. Both gymnosperms (cone-bearing plants) and angiosperms (flowering plants) produce pollen as part of sexual reproduction. Pollen grains have characteristic walls with distinctive ornamentation that permit their identification. The production and emission of pollen are governed by interacting environmental factors, such as photoperiod, temperature, and wa- 
ter stress (Dahl et al., 2013). Pollen is primarily dispersed in the atmosphere by insects or wind. Wind-pollinated plants are called anemophilous and they produce huge amounts of pollen grains which, once airborne, are responsible of allergenic reactions when inhaled by humans (Cecchi, 2013). Fungal spores are a biological component that can be found any time of the year in the atmosphere (Lacey, 1981; Burch and Levetin, 2002). Environmental variables, such as temperature and moisture, can influence growth and reproduction in fungi which makes airborne spore concentrations to fluctuate seasonally (Grinn-Gofrón and Strzelczak, 2008; Pakpour et al., 2015). However, it has also been observed that local climate, vegetation patterns, and management of landscape are governing parameters for the overall spore concentration, while the annual variations caused by weather, although not negligible, are of secondary importance (Skjøth et al., 2016). Fungi are, after pollen, the second most important producers of outdoor airborne allergens (Weikl et al., 2015). Their presence can cause human health problems (mainly allergies) and crop infections (phytopathology) (e.g., Burge and Rogers, 2000; Simon-Nobbe et al., 2008). Up to $80 \%$ of asthmatics are sensitized to fungal allergens (Lopez and Salvaggio, 1985 ) and a disease pattern of severe asthma with fungal sensitization has been recently proposed (Denning et al., 2006).

Worldwide many people living in large cities suffer from allergies linked to the presence of atmospheric pollen and fungal spores. In the industrialized countries of central and northern Europe, up to $15 \%$ of the population is sensitive to pollen allergens (WHO, 2003; Cecchi, 2013). In Europe the most common types of pollen are Ambrosia, Alnus, Artemisia, Betula, Corylus, Chenopodiaceae, Cupressaceae/Taxaceae, Olea, Platanus, Poaceae, Quercus, and Urtica/Parietaria (Skjøth et al., 2013). Although their concentration is monitored daily at ground level by aerobiological networks (Scheifinger et al., 2013; Karatzas et al., 2013), very little is known on their vertical distribution and their long/short-range transport (Sofiev et al., 2013) although an increase in interest has arisen very recently in the aerosol lidar community (Sassen, 2008; Noh et al., 2013a, b). Sassen (2008) reported on lidar measurements in the lower atmosphere of birch pollen plumes from the boreal forest of Alaska. Noh et al. (2013a) retrieved optical properties with a polarization-sensitive lidar for Pinus and Quercus pollen in South Korea. Noh et al. (2013b) reported on the vertical distribution of the same pollen event observed with lidar and on the dependency of its diurnal variations upon the meteorological conditions (temperature, relative humidity, and wind speed). Sugimoto et al. (2012) developed a lidar spectrometer system with high spectral resolution which showed promising results for investigating the vertical structure of biological particles.

In the Mediterranean city of Barcelona, Spain, the most abundant pollen taxa are Quercus (27.4\% of the total pollen), Pinus, Platanus, Cupressaceae, Olea, Urticaceae, Poaceae, Chenopodiaceae, Plantago, Moraceae, Fraxinus, Castanea, and Populus (1\%) according to the Aerobiological Network of Catalonia (http://lap.uab.cat/aerobiologia) and based on pollen concentrations measured in the period 1994-2015. Barcelona is the Spanish city which presents the longest mean pollen season of Platanus pollen. Maximum daily counts occur generally during the second half of March (Díaz de la Guardia et al., 1999). Platanus hispanica is responsible of the most frequent pollen sensitizations (37\%) detected in Barcelona (Puiggròs et al., 2015). Pinus is one of the most abundant pollen taxa in Spain (Belmonte and Roure, 1991; De Linares et al., 2014). In Barcelona, Pinus pollination occurs in two phases: the most important one happens from March to May and the other in June-July. Regarding airborne fungal spores, Cladosporium is the most abundant taxon in Barcelona, representing up to $44 \%$ of the total fungal spore spectrum. It is present all year round and shows the highest concentrations in April-May and November (Infante et al., 1999; see also http://lap.uab.cat/aerobiologia). This paper aims at investigating the possible correlation between pollen near-surface concentration and columnar properties measured during a 5-day pollination event in Barcelona. The data set is composed of continuous measurements at a temporal resolution of $1 \mathrm{~h}$. The influence of the meteorological conditions and the solar radiation on the pollen dispersion is also investigated. This contribution relates for the first time near-surface and lidar measurements of pollen in a large $\mathrm{Eu}-$ ropean city.

The paper is organized as follows: Sect. 2 presents the methods used to count the pollen and spore taxa and also describes the lidar instrument used and the method employed to estimate the pollen optical properties. Pollen and spores measured in Barcelona are first analyzed with daily mean concentration values and lidar quick looks (time-altitude contour plots) in Sect. 3. The analysis of the temporal evolution of hourly concentrations and meteorological parameters completes this section. Section 4 is dedicated to the investigation of possible correlations between near-surface pollen concentration and the vertical distribution of a series of structural and optical properties. Finally Sect. 5 enlightens us on the relationship between the vertical transport of airborne pollen and the solar radiation.

\section{Instrumentation and method}

\subsection{Pollen and spores sampling instrumentation, $\mathbf{P M}_{10}$, and meteorological data}

Airborne pollen and spore data were collected by the Aerobiological Network of Catalonia at the sampling station situated on the roof of a building in the city center of Barcelona $\left(2.164^{\circ} \mathrm{E}, 41.394^{\circ} \mathrm{N}\right)$. Samples were obtained using volumetric suction pollen-spore trap based on the impact principle (Hirst, 1952), the standardized method in European aerobiological networks. The Hirst sampler is calibrated to han- 
dle a flow of $10 \mathrm{~L}$ of air per minute, thus matching the human breathing rate. Pollen and spores are impacted on a cylindrical drum covered by a Melinex film coated with a $2 \%$ silicon solution as trapping surface. The drum was changed weekly and the exposed tape was cut into seven pieces, each one corresponding to 1 day, which were mounted on separate glass slides. Pollen and spores were counted under a light microscope at $600 \mathrm{X}$ magnification. Daily average pollen and spore counts were obtained following the standardized Spanish method (Galán Soldevilla et al., 2007), consisting in running four longitudinal sweeps along the $24 \mathrm{~h}$ slide for daily data, identifying and counting each pollen and spore type found. To obtain the hourly concentrations, 24 continuous transversal sweeps separated every $2 \mathrm{~mm}$ along the dailysample slide were analyzed, since the drum rotates at a speed of $2 \mathrm{~mm} \mathrm{~h}^{-1}$. Daily and intra-diurnal (hourly) pollen and spore concentrations are obtained converting the pollen and spore counts into particles per cubic meter of air, taking into account the proportion of the sample surface analyzed and the air intake of the Hirst pollen trap $\left(10 \mathrm{~L} \mathrm{~min}^{-1}\right)$.

$\mathrm{PM}_{10}$ measurements were acquired at the "Eixample" station of the Xarxa de Vigilància i Previsió de la Qualitat de l'Aire (XVPCA, the Catalonian network for monitoring and forecasting the air quality). It is located at $1.2 \mathrm{~km}$ to the southwest of the pollen sampling instrumentation.

Meteorological data were recorded in the "Zona Universitaria" area of Barcelona, at approximately $0.6 \mathrm{~km}$ southsoutheast of the lidar site.

\subsection{The Barcelona Micro Pulse Lidar (MPL)}

The profiles of the particle backscatter coefficient and the particle depolarization ratio were measured with the Barcelona MPL system, model MPL-4B. The system is located in the "Zona Universitaria" area of the city, on the roof of the Remote Sensing Lab (RSLab) building in the North Campus of the Universitat Politècnica de Catalunya $\left(2.112^{\circ} \mathrm{E}, 41.389^{\circ} \mathrm{N} ; 115 \mathrm{~m}\right.$ a.s.l.), approximately $1 \mathrm{~km}$ from Sierra de Collserola and $7 \mathrm{~km}$ from the sea. It is located at $4.4 \mathrm{~km}$ to the west of the pollen sampling instrumentation. The system should become very shortly part of the MPLNET (Micro Pulse Lidar Network, http://mplnet.gsfc.nasa.gov/) network. The MPL system is a compact, eye-safe lidar designed for full-time unattended operation (Spinhirne, 1993; Campbell et al., 2002; Flynn et al., 2007; Huang et al., 2010). It uses a pulsed solid-state laser emitting low laser pulse energy $(\sim 6 \mu \mathrm{J})$ at a high pulse rate $(2500 \mathrm{~Hz})$ and a co-axial "transceiver" design with a telescope shared by both transmit and receive optics. The Barcelona MPL optical layout uses an actively controlled liquid crystal retarder which makes the system capable to conduct polarization-sensitive measurements by alternating between two retardation states (Flynn et al., 2007). The signals acquired in each of these states are recorded separately and called "co-polar" and "cross-polar".
In nominal operation the raw temporal and vertical resolutions are $30 \mathrm{~s}$ and $15 \mathrm{~m}$, respectively.

The linear volume depolarization ratio, $\delta^{\mathrm{V}}$, is defined as

$\delta^{\mathrm{V}}(z)=\frac{\beta_{\perp}(z)}{\beta_{\|}(z)}=\frac{P_{\perp}(z)}{P_{\|}(z)}$,

where $\beta_{-}$and $\beta_{\|}$denote the total (particles + molecules) perpendicular and parallel backscatter coefficient, respectively, and $P_{-}$and $P_{\| \mid}$represent the perpendicular and parallel backscatter powers, respectively. According to Gimmes$\operatorname{tad}(2008) \delta^{\mathrm{V}}$ can also be expressed as a function of a factor $d$, which has a range of $0-1$ and is related to the propensity of the scattering medium to preserve the incident polarization:

$\delta^{\mathrm{V}}(z)=\frac{d}{2-d}$.

In the case of a linear polarization lidar, $d=0$ indicates that no depolarization occurs, while $d=1$ indicates that the returned beam is completely depolarized. By adapting the notations of Flynn et al. (2007), especially in Eqs. (1.4) and (1.6), one can formulate the linear volume depolarization ratio for the MPL system as

$\delta^{\mathrm{V}}(z)=\frac{P_{\mathrm{cr}}(z)}{P_{\mathrm{co}}(z)+P_{\mathrm{cr}}(z)}$,

where $P_{\mathrm{cr}}$ and $P_{\mathrm{co}}$ represent the MPL cross- and co-polar channels, respectively.

The linear particle depolarization ratio, $\delta^{\mathrm{p}}$, can then be determined by (Freudenthaler et al., 2009)

$$
\begin{aligned}
\delta^{\mathrm{p}}(z) & =\frac{\beta_{\perp}^{\mathrm{p}}(z)}{\beta_{\|}^{\mathrm{p}}(z)} \\
& =\frac{\left[1+\delta^{\mathrm{m}}\right] \delta^{\mathrm{V}}(z) R(z)-\left[1+\delta^{\mathrm{V}}(z)\right] \delta^{\mathrm{m}}}{\left[1+\delta^{\mathrm{m}}\right] R(z)-\left[1+\delta^{\mathrm{V}}(z)\right]},
\end{aligned}
$$

where $\beta_{\perp}^{\mathrm{p}}$ and $\beta_{\| \mid}^{\mathrm{p}}$ are the particle perpendicular and parallel backscatter coefficients, respectively, $\delta^{\mathrm{m}}$ is the molecular depolarization ratio and $R$ is the backscatter ratio, which is defined as

$R(z)=\frac{\beta^{\mathrm{m}}(z)+\beta^{\mathrm{p}}(z)}{\beta^{\mathrm{m}}(z)}$,

where $\beta^{\mathrm{m}}$ and $\beta^{\mathrm{p}}$ denote the molecular and particle backscatter coefficient, respectively, of the total (perpendicular + parallel) returned signal. According to the MPL optical requirements in the receiving system the spectral filtering is performed by filters with a spectral band $\leq 0.2 \mathrm{~nm}$. This number produces a temperature-independent molecular depolarization ratio of $\delta^{\mathrm{m}}=0.00363$ according to Behrendt and Nakamura (2002).

The particle backscatter coefficient, $\beta^{\mathrm{p}}$, was retrieved with the two-component elastic algorithm (also known as the Klett-Fernald-Sasano method; Fernald, 1984; Sasano and 
Nakane, 1984; Klett, 1985) with a constant lidar ratio of $50 \mathrm{sr}$ and applied to the total lidar signal, $P$, reconstructed from the MPL lidar signals as (Flynn et al., 2007)

$P(z)=P_{\mathrm{co}}(z)+2 P_{\mathrm{cr}}(z)$.

The value of $50 \mathrm{sr}$ is motivated by two previous studies. First, it falls in the range of the mean columnar lidar ratios, 46-69 sr, found in Barcelona during the period from February to April and calculated over a period of 3 years (Sicard et al., 2011). In that work the columnar lidar ratio was retrieved with the two-component elastic lidar inversion algorithm constrained with the aerosol optical depth (AOD) from a sun photometer (Landulfo et al., 2003; Reba et al., 2010). Second, Noh et al. (2013b) used the same method and found a mean columnar lidar ratio of $50 \pm 6$ sr during a 6-day pollination event (mostly dominated by Pinus and Quercus pollen) in South Korea. At the peak of the event the pollen AOD represented up to $35 \%$ of the total AOD.

\subsection{Determination of pollen optical and structural properties}

Pollen has formerly been distinguished from other particle types thanks to its depolarization capabilities (Sassen, 2008; Noh et al., 2013a, b). Although many types of pollen have regular shapes (circular, spherical, elliptical, ovoid, etc.), they cannot be considered spherical from the point of view of light scattering because they do not generate Mie patterns expected from a sphere of equivalent size. The reason lies in surface imperfections of pollen grains and inhomogeneous refractive indices inside the grains

When the atmospheric particle load can be assumed as the external mixing of one type of depolarizing particles (here, the pollen) with another type of much less depolarizing particles, the method suggested by Shimizu et al. (2004) allows us to separate the contribution ratio of both types of particles. The same rationale leading to Eq. (4) allows us to define a pollen (highly depolarizing particles) contribution ratio to the total particle depolarization ratio, $\mathrm{CR}_{\mathrm{pol}}$, expressed as

$\mathrm{CR}_{\mathrm{pol}}(z)=\frac{\left[\delta^{\mathrm{p}}(z)-\delta_{\text {no-pol }}\right]\left[1+\delta_{\mathrm{pol}}\right]}{\left[\delta_{\mathrm{pol}}-\delta_{\text {no-pol }}\right]\left[1+\delta^{\mathrm{p}}(z)\right]}$,

where $\delta_{\text {no-pol }}$ and $\delta_{\text {pol }}$ are the particle depolarization ratios of all particle types except pollen (weakly depolarizing) and of only the pollen (depolarizing), respectively. One can check easily whether no pollen is present $\left(\delta^{\mathrm{p}}=\delta_{\text {no-pol }}\right.$ and Eq. (7) leads to $C R_{\text {pol }}=0$ ) and whether only pollen is present ( $\delta^{\mathrm{p}}=\delta_{\text {pol }}$ and Eq. (7) leads then to $\left.\mathrm{CR}_{\text {pol }}=1\right)$. The pollen backscatter coefficient, $\beta_{\mathrm{pol}}$, is simply calculated as

$\beta_{\mathrm{pol}}(z)=\mathrm{CR}_{\mathrm{pol}}(z) \beta^{\mathrm{p}}(z)$.

The contribution ratio is sensitive to the selection of $\delta_{\text {no-pol }}$ and $\delta_{\text {pol }}$, which are determined either empirically or taken from references. To fix the value of $\delta_{\text {no-pol }}$ we searched for a clear-sky day prior to the pollination event without longrange transport aerosols. Such conditions were fulfilled on 15 March around 12:00 UT. On that day a well-mixed atmospheric boundary layer (ABL) developed. At 12:00 UT the ABL height was $\sim 1.2 \mathrm{~km}$ and the AOD 0.18 . The particle depolarization ratio was constantly $\sim 0.03$ in the whole ABL. We have taken $\delta_{\text {no-pol }}=0.03$. In the literature very few information on measurements of pollen depolarization ratios is available. The choice of $\delta_{\text {pol }}$ is deferred to Sect. 4 , after the analysis of the individual profiles of $\delta^{\mathrm{p}}$, in order to have as much information as possible. A short discussion on the uncertainty of $\mathrm{CR}_{\mathrm{pol}}$ and $\beta_{\mathrm{pol}}$ linked to the choice of $\delta_{\mathrm{pol}}$ is also discussed in Sect. 4.

Finally we also calculated the vertical height, $h_{\mathrm{pol}}$, up to which the pollen plume extends. As it is shown in Sect. 4, the pollen plume is characterized during the whole pollination event by a near-constant or slightly decreasing profile of $\beta_{\mathrm{pol}}$. From this aspect the structure of the pollen plume is much simpler than the ABL structure usually found in Barcelona (Sicard et al., 2006). This allows us to use a simple threshold method such as the one used to estimate the ABL height by Melfi et al. (1985) and Boers et al. (1988). After several tests we empirically set a threshold of $0.055 \mathrm{Mm}^{-1} \mathrm{sr}^{-1}$ and defined $h_{\mathrm{pol}}$ as the height at which $\beta_{\text {pol }}(z)<0.055 \mathrm{Mm}^{-1} \mathrm{sr}^{-1}$. This empirical threshold guarantees that the integral of $\beta_{\mathrm{pol}}(z)$ up to $h_{\mathrm{pol}}$ represents at least $99 \%$ of its integral over the whole atmospheric column.

\section{Temporal variation of pollen and spore taxa near-surface and columnar properties}

In the second half of March 2015 a strong anticyclone positioned in the Atlantic Ocean west of the Portuguese coast generated northwesterly winds in the northeastern part of the Iberian Peninsula. In Barcelona, the synoptic conditions resulted in marked, off-shore winds in altitude yielding to relatively clear skies and preventing long-range transport of highly depolarizing aerosols like mineral dust over Barcelona. To confirm that mineral dust was not transported over Barcelona during the pollination event, we used the dust transport models BSC-DREAM8b v2 (Barcelona Supercomputing Center - Dust Regional Atmospheric Model 8 bins) and NMMB/BSC-DUST (Nonhydrostatic Multiscale Meteorological Model on the B grid/Barcelona Supercomputing Center - Dust), as well as HYSPLIT (Hybrid Single Particle Lagrangian Integrated Trajectory) back trajectories (not shown).

On a daily basis 93 pollen types and 40 fungal spore types are counted routinely at the Aerobiological Network of Catalonia. The daily variation of the concentration of the four most abundant pollen (Platanus, Pinus, and Cupressaceae) and spore (Cladosporium) taxa and the total (pollen + spore) is represented in Fig. 1a for a period surrounding the peak of 
the pollination event under study. Figure $1 b$ shows the fraction of each one of the four most abundant taxa to the total (pollen + spore). During the pollination event, 26-31 March, the total concentration varies between 1082 and 2830 pollen and fungal spore per cubic meter a day. Three days before (23 March) and after ( 3 April) the event, values of 275 and $368 \mathrm{~m}^{-3}$ are registered, respectively. The most abundant taxon is Platanus, which represents between 48 and $71 \%$ of the total concentration during the pollination event. This range of values is higher than the annual fraction of Platanus to total pollen, $46.3 \%$, estimated by Gabarra et al. (2002) over the period 1994-2000 in the city of Barcelona. The Platanus daily concentration reaches a maximum of $1703 \mathrm{~m}^{-3}$ on 31 March. This value is in the lower part of the range of daily maxima $\left(1543-2567 \mathrm{~m}^{-3}\right)$ observed per year over the period 1994-2000 by Gabarra et al. (2002). Pinus is the second most abundant taxon, representing between 18 and $30 \%$ of the total concentration during the pollination event and reaches a maximum of $803 \mathrm{~m}^{-3}$ on 30 March. During the whole event Platanus and Pinus pollen types represent $80 \%$ or more of the total concentration. Pinus is the taxon that presents the highest relative increase since its fraction passes from values lower than $10 \%$ before the event to up to values ranging from 18 to $30 \%$ during the event. The third most abundant taxon is Cladosporium spore, which represents between 6 and $11 \%$ of the total concentration during the pollination event and reaches a maximum of $224 \mathrm{~m}^{-3}$ on 31 March. This value is of the order of magnitude of the daily means observed during the month of March $\left(\sim 200 \mathrm{~m}^{-3}\right)$ by Infante et al. (1999) over a 6-year period in the city of Barcelona. Finally the fourth most abundant taxon is $\mathrm{Cu}-$ pressaceae which does not count for more than $5.4 \%$ (on 27 March) of the total concentration. With a maximum peak of $74.9 \mathrm{~m}^{-3}$ (on $28 \mathrm{March}$ ), this event is of rather low intensity for Cupressaceae as it falls at the end of the pollen season for that taxon according to Belmonte et al. (1999).

The temporal evolution of the profiles of the particle backscatter coefficient and the volume linear depolarization ratio during the pollination event is shown in Fig. 2. Aerosols are present every day up to $2.5-3 \mathrm{~km}$. However, most of the aerosol load is found below approximately $1.5 \mathrm{~km}$. Near the ground $(<0.5 \mathrm{~km})$ high values of $\beta^{\mathrm{p}}\left(4 \mathrm{Mm}^{-1} \mathrm{sr}^{-1}\right)$ are found on almost all days. Between 0.5 and $1.5 \mathrm{~km}$ the green color code indicates values of $\beta^{\mathrm{p}}$ not higher than $2-2.5 \mathrm{Mm}^{-1} \mathrm{sr}^{-1}$ (except on $26 \mathrm{March}$, when clouds are present below $2 \mathrm{~km}$ before 08:00 UT). In general, two regimes are observed every day: an increase in amplitude and height starting around 10:00 UT which persists until the night and a less pronounced nighttime regime starting usually after midnight. On 31 March one sees a layer appearing after 11:00 UT with very large values of $\beta^{\mathrm{p}}\left(>5 \mathrm{Mm}^{-1} \mathrm{sr}^{-1}\right)$ and confined in the first $0.5 \mathrm{~km}$ of the ABL. This increase of $\beta^{\text {p }}$ in the bottom part of the ABL has no impact on the volume depolarization ratio vertical distribution (Fig. 2b), which suggests that it is due to non-depolarizing particles. The green

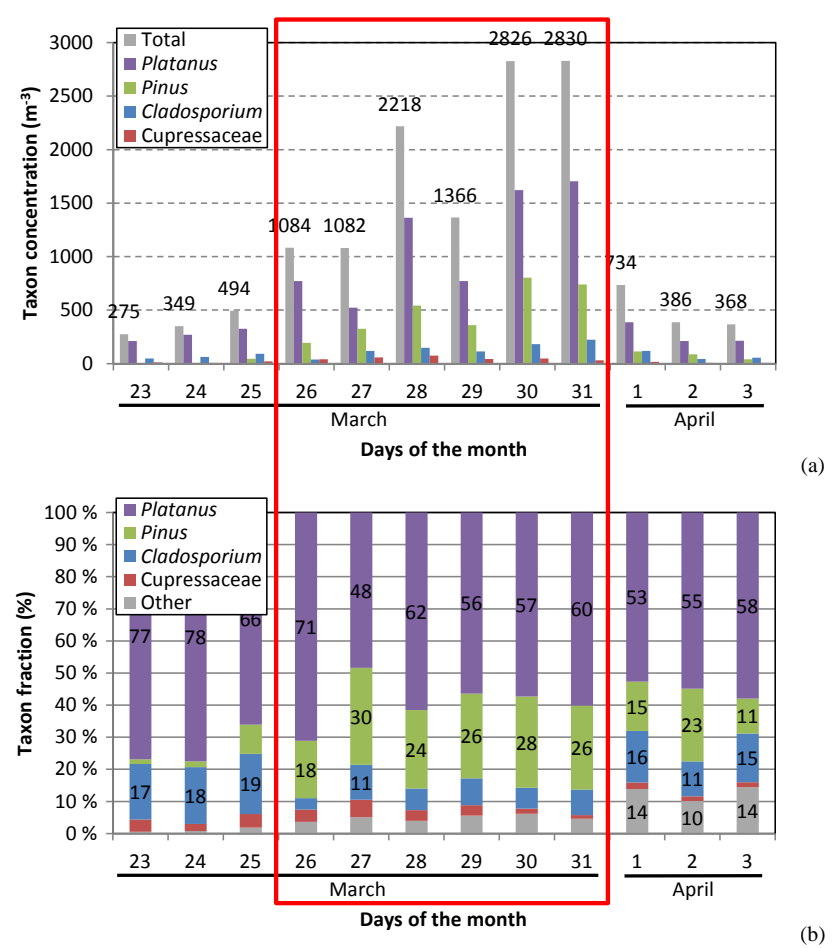

Figure 1. (a) Daily concentration of the four most abundant pollen (Platanus, Pinus and Cupressaceae) and fungal spore (Cladosporium) taxa and total (pollen + spore); (b) fraction of these four taxa during the period 23 March-3 April 2015. The red rectangle indicates the intense pollination event. The values of the total concentrations are reported in Fig. 1a. The fractions higher than $10 \%$ are reported in Fig. 1b.

color code volume depolarization ratio shown in Fig. $2 \mathrm{~b}$ indicates values of $\delta^{\mathrm{V}}$ near $0.02-0.03$. It is the usual value of $\delta^{\mathrm{V}}$ for background local aerosols near the surface in Barcelona. Every day around 08:00 UT a plume with $\delta^{\mathrm{V}}>0.08$ (yellowish) appears, rises up to $1.0-1.7 \mathrm{~km}$ in a few hours, and starts decreasing before 16:00 UT at a lesser rate than it rose. This diurnal pattern of $\delta^{\mathrm{V}}$ is observed on each single day of the pollination event. On the first 4 days values of $\delta \mathrm{V}$ larger than 0.08 are no longer detected after 18:00-20:00 UT. Toward the end of the event on 30 and 31 March when the pollen concentrations were the highest, values of $\delta^{\mathrm{V}}>0.08$ are still detected until 21:00-24:00 UT. The highest values of $\delta^{\mathrm{V}}$ are detected on 30 March and are of the order of 0.22. This maximum value is higher than the peak value of 0.15 observed by Noh et al. (2013b) for Pinus and Quercus pollen in South Korea and lower than $\delta^{\mathrm{V}}=0.30$ measured by Sassen (2008) for birch pollen plumes from the boreal forest of Alaska.

Because of the presence of clouds near the ABL top in the first part of 26 March (Fig. 2b), this day is discarded in the rest of the paper and from now on we will focus only on the period 27-31 March. To gain an insight into the temporal variations of the pollen and spore taxa concentration, we performed counting on an hourly basis for the period 27 


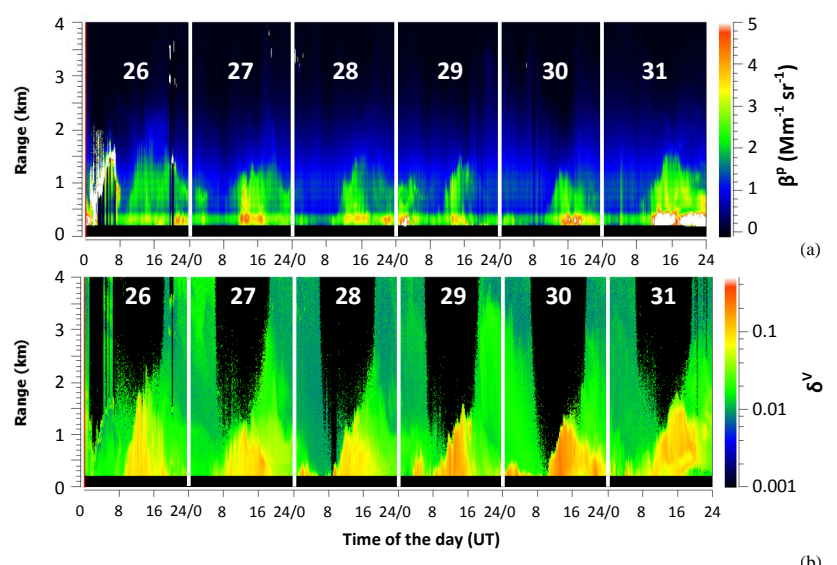

Figure 2. Five-minute resolution time-range plots of the (a) particle backscatter coefficient $\left(\beta^{\mathrm{p}}\right)$ and (b) volume depolarization ratio $\left(\delta^{\mathrm{V}}\right)$ during 26-31 March 2015.

31 March. The method used is described in Sect. 2.1. Although all pollen and spore taxa were counted, in the following we will only show the results of the total pollen (spore is no longer taken into account) and of the two most abundant pollen types: Platanus and Pinus. The two main reasons for that choice are that (1), as found earlier, Platanus and Pinus pollen represent more than $80 \%$ of the total (pollen + spore) taxa and (2) the ratio of total spore to total pollen is less than $13 \%$ during the period 27-31 March.

Many works have investigated the influence of the meteorological conditions, such as relative humidity $(\mathrm{RH})$, temperature $(T)$, wind speed, the number of sunshine hours, and rainfall, on the release and transport of pollen in the atmosphere (Raynor et al., 1973, Mandrioli et al., 1984; Hart et al., 1994; Alba et al., 2000; Jato et al., 2000; Bartková-Šcevková, 2003; Vázquez et al., 2003; Latorre and Caccavari, 2009, among others). On the one hand, relative humidity and temperature greatly affect the release of pollen in the atmosphere by influencing the extent to which individual pollen grains dehydrate. For example, a low relative humidity associated with a high temperature will tend to increase the number of airborne pollen grains by decreasing their specific gravity. The relation of pollen with water comes from its hydrophilic properties and from the fact that it is prone to harmomegathic movement (accommodation of volume change when it absorbs water; Wodehouse, 1935). The duration of the sunshine has also proved to have an influence on the pollen release (Alba et al., 2000). On the other hand, wind speed plays a major role in the transport and dispersion of airborne pollen: high daytime wind speed may facilitate the dispersion of airborne pollen in the atmosphere (Latorre and Caccavari, 2009, and references therein). The effect of rainfall is to reduce the number of airborne pollen grains by washing out the atmosphere. During the pollination event presented in this work, no rain was detected.
In Fig. 3 we present the hourly temporal variations of (1) Platanus, Pinus and total pollen concentration during the period 27-31 March, together with (2) relative humidity, (3) temperature, and (4) wind speed. In Fig. 3b we also indicated the time of the maximum pollen concentration and pollen AOD on each day. The pollen AOD, $\mathrm{AOD}_{\text {pol }}$, was obtained by integrating the profile of $\beta_{\mathrm{pol}}$ from the ground up to $h_{\text {pol }}$ and multiplying the result by the same lidar ratio used in the lidar inversion, $50 \mathrm{sr}$ (see Sect. 2.2). With the exception of 31 March, the pollen number concentration at ground level follows a clear diurnal cycle (Fig. 3a). On 31 March, no clear difference is observed between day and night. Platanus and Pinus concentration reaches maximum peaks of $\sim 4700 \mathrm{~m}^{-3}$ on 31 March and $1200 \mathrm{~m}^{-3}$ on 30 March, respectively. Maximum peaks of the total pollen concentration higher than 5000 and $6000 \mathrm{~m}^{-3}$ are reached on 30 and 31 March, respectively. They are associated with absolute peaks of Platanus and relative peaks of Pinus. Interestingly a release cycle is visible each day: the diurnal variation is marked with several relative peaks along the day that are usually distant in time by 2 to $4 \mathrm{~h}$. Platanus and Pinus peaks are not necessarily correlated. The fact that Platanus variations are shaper than Pinus ones may be explained by the size difference between both pollen types: while Platanus longest diameter (on the polar axis) varies between 21 and $28 \mu \mathrm{m}$, it varies between 60 and $74 \mu \mathrm{m}$ for Pinus (https://www.polleninfo.org/AT/en/allergy-infos/ aerobiologics/pollen-atlas.html?letter=P). Pollen size is known to be a factor affecting not only pollen release but also pollen settlement to the ground (McCartney, 1994).

The relative humidity and temperature hourly evolution shows a clear diurnal cycle (Fig. 3b): a relative humidity decrease associated with a temperature increase is observed during daytime while the opposite occurs during nighttime. Daytime RH $(T)$ values are found in the range of $40-60 \%$ $\left(17-25^{\circ} \mathrm{C}\right)$ while nighttime values are found in the range of $65-90 \%\left(12-18^{\circ} \mathrm{C}\right)$. While no marked trend is observed on the relative humidity along the pollination event, a temperature day-to-day increase is observed, the daily mean temperature passing from 15.2 to 17.5 to 16.6 to 18.5 to $17.9^{\circ} \mathrm{C}$ between 27 and 31 March. The correlation coefficient between the daily mean temperature and the daily total pollen concentration is 0.95 , indicating a strong dependence of pollen release upon temperature. The correlation coefficient between the daily mean relative humidity and the daily total pollen concentration, -0.18 , is negative but much lower (in absolute value) than the one for temperature. Except on 28 and 31 March (when wind speeds higher than $6 \mathrm{~m} \mathrm{~s}^{-1}$ are detected in the first half of the day), the daytime wind speed usually oscillated between 2 and $3 \mathrm{~m} \mathrm{~s}^{-1}$ (with gusts at $\sim 4.5 \mathrm{~m} \mathrm{~s}^{-1}$ ), which corresponds to a light breeze. From 27 to 31 March, the daily wind speed varies from 1.6 to 2.5 to 1.5 to 3.7 to $2.4 \mathrm{~m} \mathrm{~s}^{-1}$, similarly to the daily mean temperature. The correlation coefficient between daily wind speed 


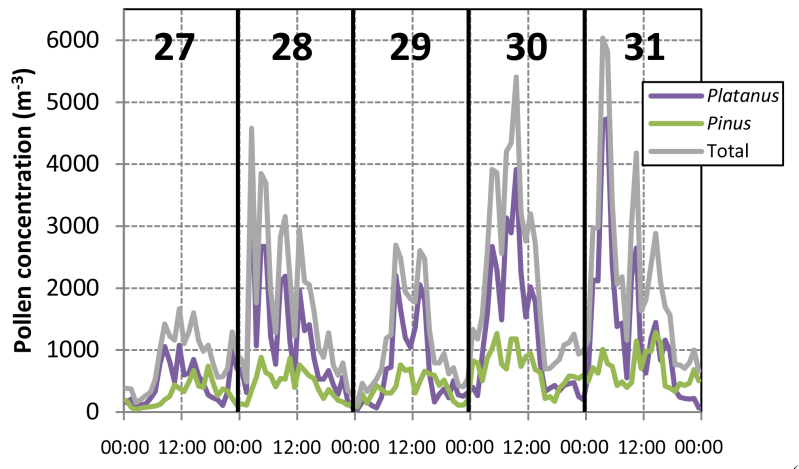

(a)
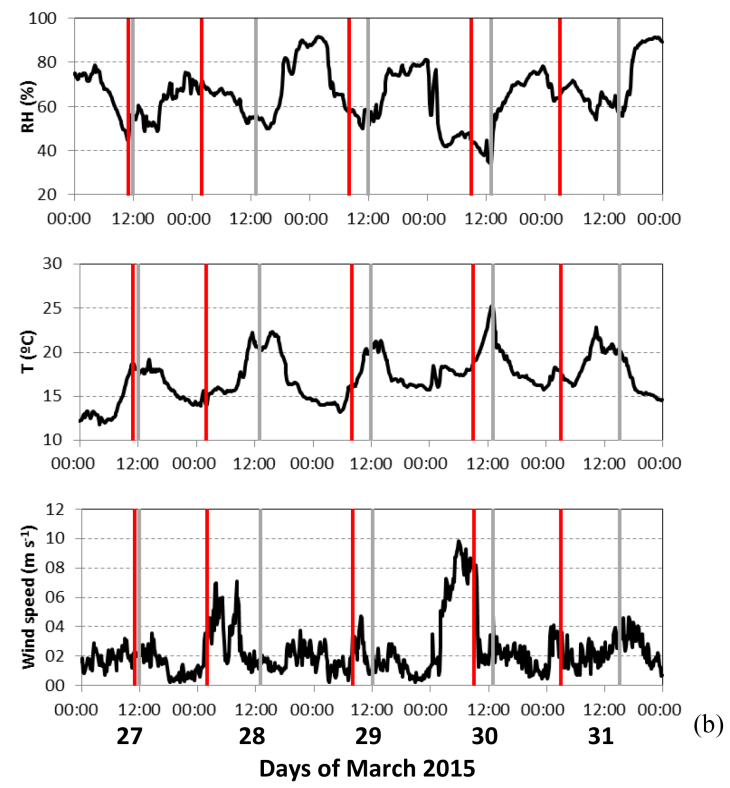

Figure 3. Hourly temporal evolution (a) of the concentration of the two most abundant pollen taxa (Platanus and Pinus) and (b) of the meteorological data: relative humidity $(\mathrm{RH})$, temperature $(T)$, and wind speed from 00:00 UT on 27 March until 24:00 UT on 31 March 2015. The red and grey vertical lines indicate the time of the maximum pollen concentration and pollen optical depth, respectively, on each day.

and total pollen concentration is 0.82 , indicating a strong dependence of pollen release also upon wind speed.

Each day the time of the maximum peak of the total pollen concentration (red vertical lines, Fig. 3b) occurs between 02:00 and 11:00 UT, while that of $\mathrm{AOD}_{\text {pol }}$ (grey vertical lines, Fig. 3b) occurs more regularly between 12:00 and 15:00 UT. As expected, every day the $\mathrm{AOD}_{\text {pol }}$ peak follows the total pollen concentration peak. Logically, in the case of pollen of local origin, not long-range transport, a peak of the amount of pollen in the atmosphere (parameterized by $\mathrm{AOD}_{\mathrm{pol}}$ ) can only happen when a strong release of pollen at the ground level (parameterized by the pollen concentration) has previously occurred. On the one hand, surprisingly, the total pollen concentration peaks are not systematically asso- ciated with minima of RH, maxima of $T$, and/or of the wind speed, while, on the other hand, the pollen AOD peaks are systematically associated with minima of RH and maxima of $T$. The pollen AOD peaks do not present a systematic dependence upon wind speed, a result in agreement with the findings of Noh et al. (2013a), who showed a broad variation of the pollen AOD for wind speeds lower than $3 \mathrm{~m} \mathrm{~s}^{-1}$.

\section{Pollen near-surface vs. columnar properties: day-by-day analysis}

The daily temporal variation of some lidar-derived rangeresolved and columnar parameters are investigated and further compared to pollen concentrations in order to find possible correlations. Figure 4 shows the diurnal (09:0018:00 UT) profiles of the pollen backscatter coefficients and of the volume and particle linear depolarization ratios for the 5 days of the event. The top height of the pollen plume, $h_{\mathrm{pol}}$, is also indicated in the plots by horizontal grey lines. The profiles of $\delta^{\mathrm{V}}$ are characterized by a near-constant or slightly decreasing slope with increasing height which reaches zero generally sharply at $h_{\mathrm{pol}}$. The profiles of $\delta^{\mathrm{p}}$, which unlike $\delta^{\mathrm{V}}$ show only the particle depolarization effect, have a general tendency to decrease with increasing height, reflecting the gradual diminution of the number of pollen as height increases. It is also frequent to find $\delta^{p}>0.2$, especially at the beginning of the day, in the lowermost part of the ABL (below $0.3 \mathrm{~km}$ ) where most of the pollen grains concentrate.

Maxima of $\delta \mathrm{V}$ of the order of 0.22 are reached on 30 March at 12:00 UT below $0.75 \mathrm{~km}$. On that particular profile, some values of $\delta^{\mathrm{V}}$ are associated with comparatively low values of $\beta^{\mathrm{p}}\left(<2 \mathrm{Mm}^{-1} \mathrm{sr}^{-1}\right.$, not shown) and therefore with low values of the backscatter coefficient $R$, which altogether contribute to increase $\delta^{\mathrm{p}}$ according to Eq. (4). This produced values of $\delta^{\mathrm{p}}$ in the range of $0.40-0.43$ at the height of $0.5 \mathrm{~km}$. Other $\delta^{\mathrm{p}}$ maxima of 0.35 are observed on 30 March at 11:00 UT and of 0.31 on 29 and 30 March at 12:00 and 13:00 UT, respectively, all at the same height of $\sim 0.5 \mathrm{~km}$. With this in mind we now come back to the choice of $\delta_{\text {pol }}$ needed for applying Shimizu's method and left in stand-by in Sect. 2.3. Very little information is available on that subject (detailed here in chronological order).

Sassen (2008) found $\delta^{\mathrm{V}}$ maxima of 0.30 for birch pollen plumes from the boreal forest of Alaska that he described as "unusually high for aerosols and [...] comparable to irregularly shaped desert dust particles raised by dust storms". This finding implies that $\delta^{\mathrm{p}}>0.30$ in the observed pollen cloud.

In two consecutive papers Cao et al. (2010) and Roy et al. (2011) measured the linear particle depolarization at four wavelengths of several types of pollen in an aerosol chamber with a polarization-sensitive lidar. For Pinus (Platanus was not tested) they found a mean $\delta_{\text {pol }}$ of 0.41 and 0.42 , respectively. 

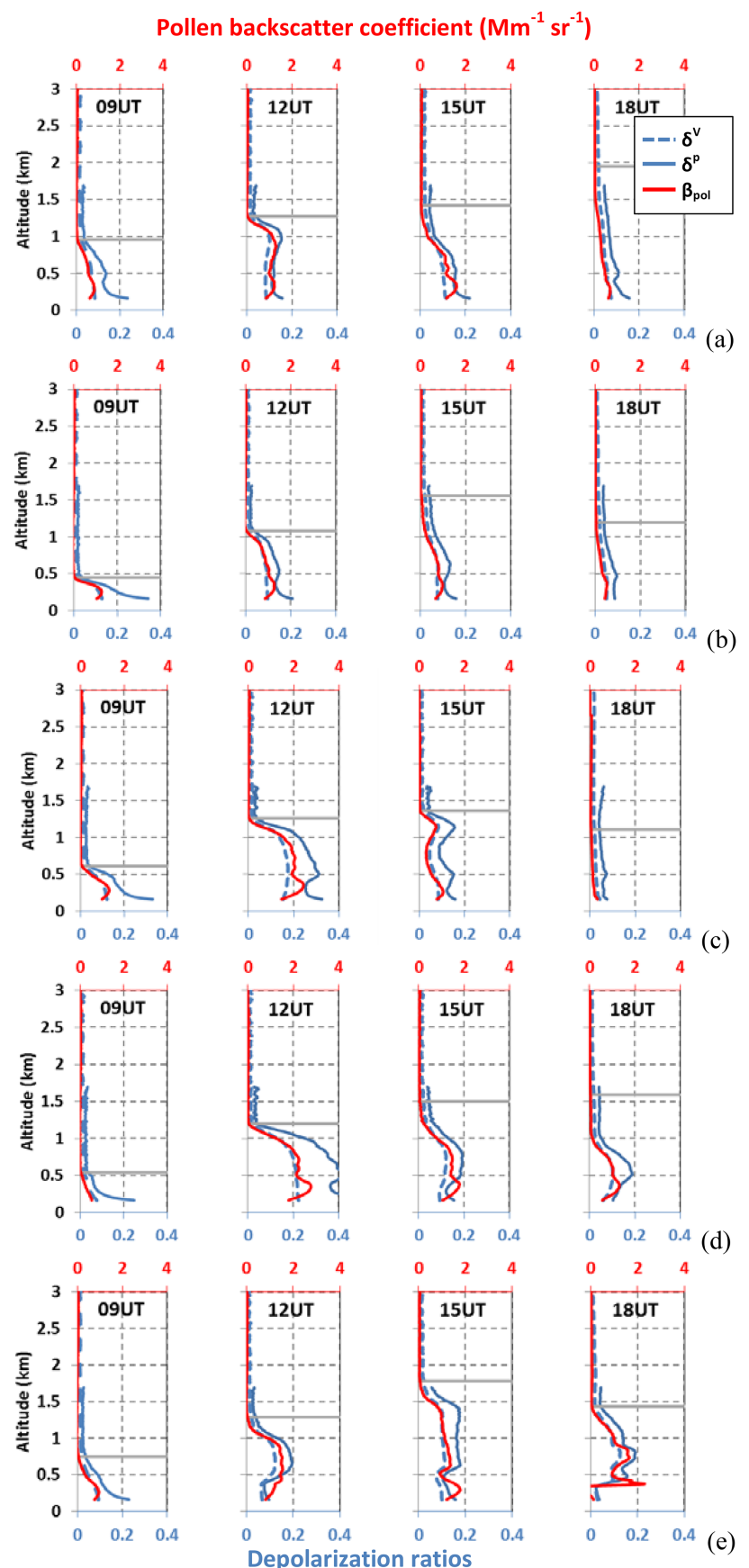

Figure 4. Diurnal time series of the hourly vertical distribution of the pollen backscatter coefficient $\left(\beta_{\mathrm{pol}}\right)$, the volume depolarization ratio $\left(\delta^{\mathrm{V}}\right)$, and the particle depolarization ratio $\left(\delta^{\mathrm{p}}\right)$ on (a) 27 , (b) 28, (c) 29, (d) 30, and (e) 31 March 2015. The grey horizontal lines indicate the pollen layer height, $h_{\text {pol }}$.

Noh et al. (2013a) used Shimizu's method with a pollen depolarization ratio equal to that of pure mineral dust, $\delta_{\text {pol }}=$ 0.34 , without further justification.

Noh et al. (2013b) found a maximum value of $\delta^{\mathrm{p}}$ of 0.23 in a cloud of Pinus and Quercus pollen mixed with local aerosols (urban haze) in South Korea. Although they used a definition of the particle depolarization ratio different from ours, we corrected the maximum value found in their paper with their Eq. (2) in order to make $\delta^{p}=0.23$ compatible with our definition. Given their estimation of urban haze depolarization ratio, 0.03 , the value of $\delta^{\mathrm{p}}=0.23$ implies $\delta_{\mathrm{pol}} \geq 0.23$.

In the present study we found maxima of $\delta^{\mathrm{p}}$ of $0.31,0.35$, and 0.43 in a cloud of Platanus and Pinus pollen mixed with local urban aerosols. Given our estimation of the local urban aerosol depolarization ratio, 0.03 (see Sect. 2.3), the former rationale implies that $\delta_{\text {pol }}$ might be greater than 0.43 , error bars aside.

It is worth noting that the maximum value of $\delta^{\mathrm{p}}$ of 0.43 observed on 30 March at 12:00 UT coincides in time with the lowest relative humidity and the highest temperature observed during the whole pollination event (see Fig. 3b). We have checked that the relative humidity and temperature profiles (not shown) measured daily by radiosoundings launched close to the lidar site were, respectively, the lowest $(\mathrm{RH}<40 \%$ up to $1 \mathrm{~km})$ and the highest $\left(T>15^{\circ} \mathrm{C}\right.$ up to $1 \mathrm{~km}$ ) on 30 March at 12:00 UT. It also follows a strong peak of pollen release at ground level at 09:00 UT (Fig. 3a) that occurred at the end of an $8 \mathrm{~h}$ period of strong winds of 6 to $10 \mathrm{~m} \mathrm{~s}^{-1}$ that might have partially cleaned the atmosphere. All in all it is reasonable to think that the aerosol load on 30 March at 12:00 UT in the first kilometer may be composed of quasi-pure pollen. Another point to take into account is the error bar associated to the calculation of the MPL particle linear depolarization ratio. To have an estimation of this error we calculated the standard deviation of the 120 profiles that composed the $1 \mathrm{~h}$ averaged profile shown in Fig. 4. For the measurement of 30 March at 12:00 UT we find a standard deviation of 0.02 at $0.5 \mathrm{~km}$ and of 0.08 at $1.0 \mathrm{~km}$. Given all the above, we fixed a pollen depolarization ratio of $\delta_{\mathrm{pol}}=0.40$.

To assess the impact of the uncertainty of the assumed pollen depolarization ratio, $\delta_{\mathrm{pol}}$, on the uncertainty of the contribution ratio of the pollen to the total particle depolarization, $\mathrm{CR}_{\mathrm{pol}}$, we consider an error $\Delta \delta_{\text {pol }}$ in the pollen depolarization ratio and write

$$
\begin{aligned}
\mathrm{CR}_{\mathrm{pol}}(z) & +\Delta C R_{\mathrm{pol}}(z) \\
& =\frac{\delta^{P}(z)-\delta_{\mathrm{no}-\mathrm{pol}}}{1+\delta^{\mathrm{p}}(z)} \frac{1+\delta_{\mathrm{pol}}+\Delta \delta_{\mathrm{pol}}}{\delta_{\mathrm{pol}}+\Delta \delta_{\mathrm{pol}}-\delta_{\mathrm{no}-\mathrm{pol}}},
\end{aligned}
$$

from which the relative error in $\mathrm{CR}_{\mathrm{pol}}, \varepsilon_{\mathrm{r} \mathrm{CR}_{\mathrm{pol}}}=\frac{\Delta \mathrm{CR}_{\mathrm{pol}}}{\mathrm{CR}_{\mathrm{pol}}}$, can be found as

$\varepsilon_{\mathrm{rCR}}=-\frac{\left(1+\delta_{\mathrm{pol}}=-\mathrm{pol}\right) \Delta \delta_{\mathrm{pol}}}{\left(1+\delta_{\mathrm{pol}}\right)\left(\delta_{\mathrm{pol}}-\delta_{\mathrm{no}-\mathrm{pol}}+\Delta \delta_{\mathrm{pol}}\right)}$.

We have calculated $\varepsilon_{\mathrm{rCR}}$ for various values of the "true" pollen depolarization ratio ranging from 0.2 to 0.5 , when $\delta_{\text {no-pol }}=0.03$ and $\delta_{\text {pol }}=0.4$ is assumed. In the range $-0.1<$ $\Delta \delta_{\text {pol }}<+0.1$ (i.e., $0.3<$ "true" pollen depolarization ra- 
tio $<0.5)$ the contribution ratio error is limited to $\pm 20 \%$ approximately.

The profile of the pollen backscatter coefficient retrieved with Shimizu's method (see Sect. 2.3) and $\left(\delta_{\text {pol }}=0.40, \delta_{\text {no-pol }}=0.03\right)$ has, like the profiles of $\delta^{\mathrm{p}}$, a general tendency to decrease with increasing height, reflecting the gradual diminution of the number of pollen as height increases. In many profiles the backscatter coefficient is higher in the first $0.5 \mathrm{~km}$ due to the presence of a number of pollen grains larger near the ground than in altitude.

Figure 5 shows the daily cycle of the days of the pollination event in terms of pollen concentration (total, Platanus, and Pinus), $\mathrm{PM}_{10}$, and a series of column-integrated lidarderived parameters $\left(\mathrm{AOD}_{\mathrm{pol}}, \mathrm{AOD}_{\mathrm{pol}} / \mathrm{AOD}, \overline{\delta^{\mathrm{V}}}\right.$, and $\left.\overline{\delta^{\mathrm{p}}}\right)$. The AOD (not shown) was obtained by integrating the profile of $\beta^{\mathrm{p}}$ in the whole column and multiplying the result by the lidar ratio of $50 \mathrm{sr}$ used in the lidar inversion. In order to be representative of the pollen plume $\overline{\delta^{\mathrm{V}}}(\overline{\delta \mathrm{p}})$ was obtained by averaging the profile of $\delta^{\mathrm{V}}\left(\delta^{\mathrm{p}}\right)$ from the ground up to $h_{\text {pol }}$, thereby limiting the averaging to the pollen plume. Table 1 gives the daily (00:00-24:00 UT) and diurnal (09:0017:00 UT) means of all the aforementioned parameters. It is worth commenting several aspects of the daily pollen variation first. The daily and diurnal correlation coefficients, the $r$ values of $\mathrm{PM}_{10}, \mathrm{AOD}, \mathrm{AOD}_{\mathrm{pol}}, \mathrm{AOD}_{\mathrm{pol}} / \mathrm{AOD}, \overline{\delta^{\mathrm{v}}}, \overline{\delta^{\mathrm{p}}}$, and $h_{\text {pol }}$ with the total pollen, Platanus, and Pinus concentration is given in Tables 2, 3, and 4, respectively.

Qualitatively, two classes of days can be distinguished: the days with no (or low) nocturnal pollen near-surface activity (27 and 29 March) and the days with nocturnal pollen activity $(28,30$, and 31 March). One sees that, when nocturnal pollen activity is observed, high pollen concentrations are reached during the night $\left(>4000 \mathrm{~m}^{-3}\right)$ and that on 2 days (28 and 31 March) the nocturnal peaks are higher than the diurnal ones. There seems to be clear indications that the nocturnal pollen activity is linked to the surface wind speed (Fig. 3b): (1) the three nights with nocturnal pollen activity correspond to the days with the highest wind speed daily means (see Sect. 3) and (2) on two nights (28 and 30 March) the nocturnal pollen activity coincides with the two periods of highest wind speeds $\left(>6 \mathrm{~m} \mathrm{~s}^{-1}\right)$. While the total pollen concentration diurnal mean is always higher than the daily mean (Table 1), the nocturnal pollen activity is able to reverse punctually this relationship for the Platanus and Pinus concentrations. A feature common to all days is the decrease of the pollen activity between 17:00 UT and midnight. The hourly temporal evolution of the $\mathrm{PM}_{10}$ is quite constant from one day to another during all 5 days of the pollination event. We note that the $\mathrm{PM}_{10}$ values are well below the hourly mean values averaged for the month of March by Querol et al. (2001) in Barcelona which oscillate roughly between 30 and $70 \mu \mathrm{g} \mathrm{m}^{-3}$. The various correlation coefficients calculated for $\mathrm{PM}_{10}$ do not yield to conclusive results: over the whole period (27-31 March) the dependence of $\mathrm{PM}_{10}$ and pollen con-
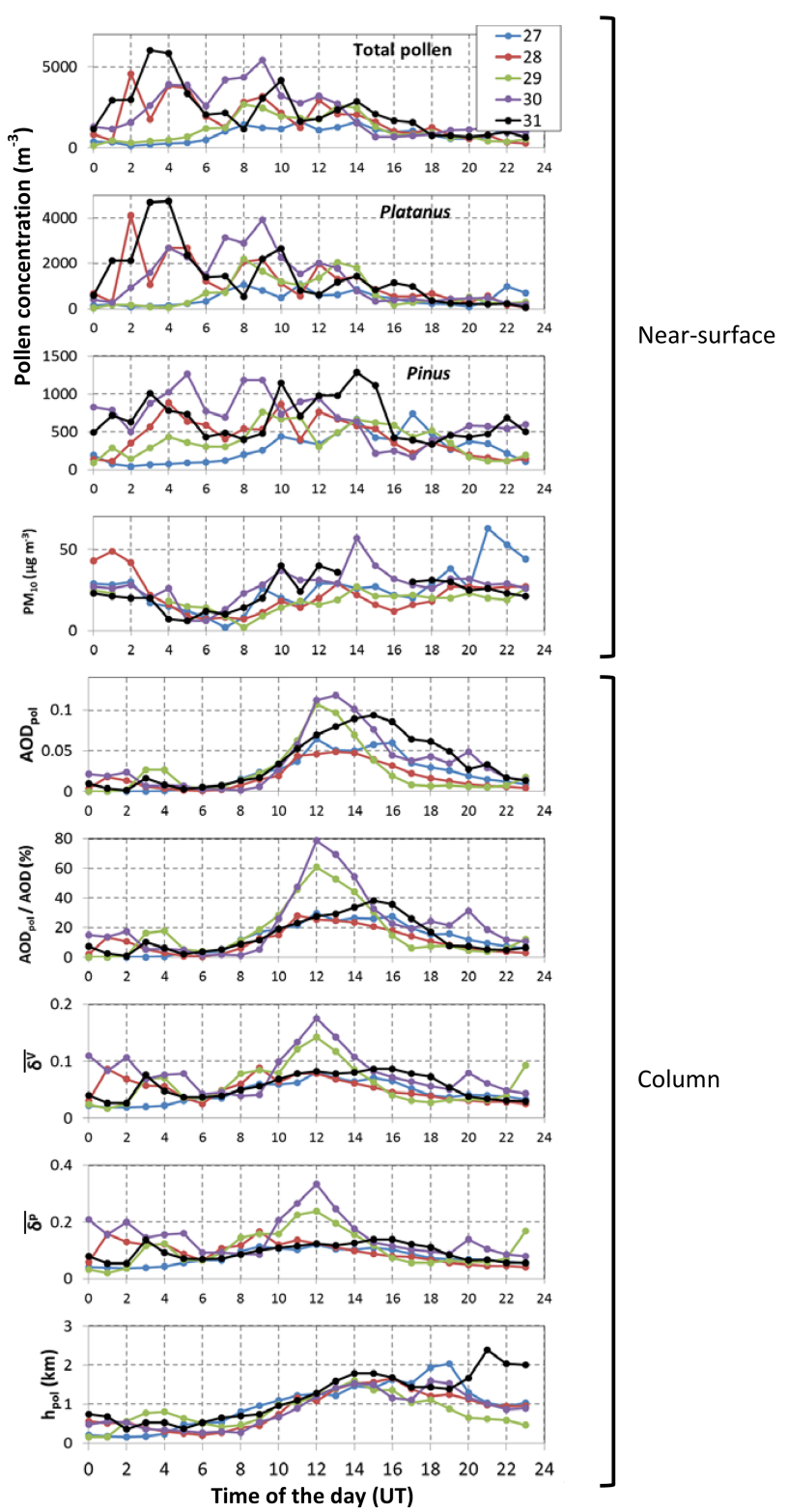

Column

Figure 5. Daily cycle for all 5 days of the pollination event of the total pollen, the Platanus and the Pinus concentration, $\mathrm{PM}_{10}$, $\mathrm{AOD}_{\mathrm{pol}}, \mathrm{AOD}_{\mathrm{pol}} / \mathrm{AOD}, \overline{\delta^{\mathrm{V}}}, \overline{\delta \mathrm{p}}$, and $h_{\mathrm{pol}}$ (see legend in the top plot).

centration is rather negative (positive) on a daily (diurnal) basis, but this relationship is not systematic on a day-by-day analysis. It is important to note that the overall positive diurnal $r$ values are the result of a circumstantial dependence: the pollen number morning increase and the everyday traffic $\mathrm{PM}_{10}$ peak occur at the same period of the day but are not linked one to another. Finally we also want to point out that $\mathrm{PM}_{10}$ samplers have a cut-off aerodynamic diameter at $10 \mu \mathrm{m}$, which is significantly smaller than the diameter of the most abundant pollen grains observed (Platanus and Pinus), 
Table 1. Mean parameters during the pollination event calculated over the periods of 00:00-24:00 and 09:00-17:00 UT.

\begin{tabular}{|c|c|c|c|c|c|c|c|}
\hline \multicolumn{8}{|l|}{ 00:00-24:00 UT } \\
\hline & Units & 27 & 28 & 29 & 30 & 31 & $27-31$ \\
\hline Conc. total & $m^{-3}$ & 865 & 1770 & 1141 & 2201 & 2237 & 1643 \\
\hline Conc. Platanus & $m^{-3}$ & 474 & 1181 & 690 & 1301 & 1384 & 1006 \\
\hline Conc. Pinus & $m^{-3}$ & 286 & 433 & 387 & 700 & 668 & 495 \\
\hline $\mathrm{PM}_{10}$ & $\mu \mathrm{g} \mathrm{m}^{-3}$ & 25.7 & 21.4 & 18.2 & 27.5 & 22.8 & 23.2 \\
\hline AOD & & 0.16 & 0.15 & 0.14 & 0.15 & 0.24 & 0.17 \\
\hline $\mathrm{AOD}_{\mathrm{pol}}$ & & 0.02 & 0.02 & 0.02 & 0.04 & 0.04 & 0.03 \\
\hline $\mathrm{AOD}_{\mathrm{pol}} / \mathrm{AOD}$ & $\%$ & 12 & 11 & 17 & 23 & 14 & 15 \\
\hline$\overline{\delta^{\mathrm{V}}}$ & & 0.04 & 0.05 & 0.06 & 0.08 & 0.06 & 0.06 \\
\hline$\overline{\delta \mathrm{P}}$ & & 0.08 & 0.10 & 0.11 & 0.15 & 0.09 & 0.10 \\
\hline$h_{\mathrm{pol}}$ & $\mathrm{km}$ & 0.98 & 0.87 & 0.81 & 0.85 & 1.18 & 0.94 \\
\hline \multicolumn{8}{|l|}{ 09:00-17:00 UT } \\
\hline & Units & 27 & 28 & 29 & 30 & 31 & $27-31$ \\
\hline Conc. Total & $m^{-3}$ & 1251 & 1909 & 1779 & 2338 & 2364 & 1928 \\
\hline Conc. Platanus & $\mathrm{m}^{-3}$ & 640 & 1169 & 1133 & 1489 & 1321 & 1150 \\
\hline Conc. Pinus & $m^{-3}$ & 458 & 547 & 580 & 635 & 832 & 610 \\
\hline $\mathrm{PM}_{10}$ & $\mu \mathrm{g} \mathrm{m}^{-3}$ & 23.9 & 17.6 & 18.6 & 34.8 & 31.7 & 25.3 \\
\hline AOD & & 0.19 & 0.17 & 0.14 & 0.16 & 0.23 & 0.18 \\
\hline $\mathrm{AOD}_{\text {pol }}$ & & 0.05 & 0.03 & 0.05 & 0.06 & 0.07 & 0.05 \\
\hline $\mathrm{AOD}_{\mathrm{pol}} / \mathrm{AOD}$ & $\%$ & 23 & 20 & 34 & 40 & 27 & 29 \\
\hline$\overline{\delta^{\mathrm{V}}}$ & & 0.07 & 0.06 & 0.09 & 0.10 & 0.08 & 0.08 \\
\hline$\overline{\delta \mathrm{p}}$ & & 0.11 & 0.11 & 0.15 & 0.18 & 0.12 & 0.14 \\
\hline$h_{\mathrm{pol}}$ & $\mathrm{km}$ & 1.31 & 1.22 & 1.18 & 1.11 & 1.37 & 1.24 \\
\hline
\end{tabular}

thus implying that no marked correlation should be expected between $\mathrm{PM}_{10}$ and pollen concentration.

We now move on to the analysis of the lidar-derived columnar parameters and their possible correlations with the near-surface pollen concentration. The daily mean AOD, which varies in the range $0.14-0.24$ (Table 1), is in the range of average values for this period of the year as reported by Sicard et al. (2011). AOD $\mathrm{Dol}_{\text {pl }}$ shows a clear diurnal cycle with maxima between 12:00 and 15:00 UT. The highest value of $\mathrm{AOD}_{\mathrm{pol}}, 0.12$, is reached on 30 March at 13:00 UT. The daily cycle and the values found here for $\mathrm{AOD}_{\mathrm{pol}}$ are similar to those of Noh et al. (2013a) in a cloud of Pinus and Quercus pollen observed in South Korea. The comparison of the plots of AOD (not shown) and $\mathrm{AOD}_{\text {pol }}$ in Fig. 5 clearly indicates that the everyday AOD increase usually starting after 09:00 UT is due to the airborne pollen. The contribution of $\mathrm{AOD}_{\mathrm{pol}}$ to the AOD passes every day from values below $20 \%$ before 09:00 UT to maxima ranging from 28 to $78 \%$ reached between 11:00 and 15:00 UT. On 29 and 30 March the maxima reach 61 and $78 \%$, respectively, while on the 3 other days $\mathrm{AOD}_{\mathrm{pol}} / \mathrm{AOD}$ stays below $40 \%$. The former maxima are quite high and suggest a strong dispersion of the pollen grains in the atmosphere. Obviously the daily and diurnal means ranging, respectively, 11-23 and 20-40\% (Table 1) are much lower than the hourly peaks. It is also interesting to note that during the last 4 days of the event the nighttime values of $\mathrm{AOD}_{\mathrm{pol}}$, although low $(<0.03)$, are not negligible. The daily evolutions of $\overline{\delta^{\mathrm{V}}}$ and $\overline{\delta^{\mathrm{p}}}$ are quantitatively very similar. Like for $\mathrm{AOD}_{\text {pol }}$ a clear diurnal cycle is visible every day with maxima of $0.18(0.33)$ for $\overline{\delta^{\mathrm{V}}}\left(\overline{\delta^{\mathrm{p}}}\right)$ reached on 30 March at 12:00 UT. The diurnal mean of $\overline{\delta^{\mathrm{V}}}$ $(\overline{\delta \mathrm{p}})$ averaged over the whole pollination event is $0.08(0.14)$. Here again the nighttime values of $\overline{\delta^{\mathrm{v}}}\left(\overline{\delta^{\mathrm{p}}}\right)$ are found nonnegligible on the last 4 days of the event. Non-negligible nighttime values of $\delta^{\mathrm{V}}$ were already observed in the timerange plots of Fig. 2. Interestingly those 4 days correspond to the 3 days previously classified as days with nocturnal pollen near-surface activity plus 29 March, which was classified as a day without nocturnal pollen activity. On 29 March the non-negligible nighttime values of $\mathrm{AOD}_{\mathrm{pol}}, \overline{\delta^{\mathrm{v}}}$, and $\overline{\delta^{\mathrm{p}}}$ coincide in time with a developed pollen plume (last plot of Fig. 5). Indeed $h_{\text {pol }}$ reaches its maximum nighttime peak, at $0.81 \mathrm{~km}$, on 29 March at 04:00 UT. This observation suggests that near-surface pollen release and pollen plume dispersion in the atmosphere are not necessarily time correlated. The daily evolutions of $h_{\text {pol }}$ are quite similar from one day to another. Heights below $0.81 \mathrm{~km}$ are found before 08:00 UT and maxima ranging $1.47-1.78 \mathrm{~km}$ are usually reached between 14:00 and 16:00 UT. Over the whole event the diurnal mean pollen height is $1.24 \mathrm{~km}$. The diurnal increase of $h_{\mathrm{pol}}$ is smoother than that of $\mathrm{AOD}_{\mathrm{pol}}, \overline{\delta^{\mathrm{V}}}$, and $\overline{\delta^{\mathrm{p}}}$. As an example, let us take $\delta^{\mathrm{V}}$ for the rationale. $\overline{\delta^{\mathrm{V}}}$ reaches a maximum almost systematically every day at 12:00 UT. While the pollen plume keeps rising vertically between 12:00 and 14:00-16:00 UT, $\overline{\delta^{\mathrm{V}}}$ decreases, evidencing a dilution effect of the atmospheric pollen: the rate of the pollen vertical distribution increase is higher than that of the release of new pollen grains, if any, in the atmosphere. Finally an unusual increase of $h_{\mathrm{pol}}$ starts on 31 March after 18:00 UT. It is associated with (1) a strong increase of AOD (not shown) due to high values of $\beta^{\mathrm{p}}\left(>5 \mathrm{Mm}^{-1} \mathrm{sr}^{-1}\right)$ in the first $0.5 \mathrm{~km}$ (see Fig. 2), (2) a decrease of $\overline{\delta^{\mathrm{V}}}$ and $\overline{\delta^{\mathrm{p}}}$, (3) values of $\delta^{\mathrm{V}}$ and $\delta^{\mathrm{p}}$ below $0.5 \mathrm{~km}$ close to the local, background values, (4) an increase of RH (see Fig. 3b), but (5) with no significant variation of the near-surface $\mathrm{PM}_{10}$ level. All in all these results suggest a slow dilution of the pollen within the ABL $(>0.5 \mathrm{~km})$ accompanied by a possible hygroscopic growth of lofted particles, probably from local origin, below $0.5 \mathrm{~km}$.

We have calculated the correlation coefficients between the near-surface pollen concentration (total, Platanus, and Pinus) and the columnar properties discussed previously in this section (Tables 2, 3, and 4). For each parameter the highest positive $r$ values have been colored in red. The highest daily (00:00-24:00 UT) $r$ values of the total pollen are on 27 March. Excepting the $\mathrm{PM}_{10}$ parameter the same occurs for Pinus, whereas for Platanus most of the highest $r$ values are found on 29 March. Although Pinus is found in lesser amounts than Platanus, it seems to influence strongly the total pollen columnar properties. The highest diurnal (09:0017:00 UT) values are found in majority on 29 March for the total pollen and Platanus and on 31 March for Pinus. This time, during the strong diurnal pollen release, the total pollen columnar properties seem to be driven by the ones of Pla- 
Table 2. Correlation coefficients of total pollen during the pollination event calculated over the periods of 00:00-24:00 and 09:0017:00 UT. Bold numbers indicate for each day the parameter with the highest positive correlation coefficient. Numbers in italic indicate for each parameter the day with the highest positive correlation coefficient.

\begin{tabular}{lrrrrrr}
\hline 00:00-24:00 UT & & & & & & \\
\hline & 27 & 28 & 29 & 30 & 31 & $27-31$ \\
\hline $\mathrm{PM}_{10}$ & 0.01 & -0.24 & -0.50 & -0.37 & -0.28 & -0.18 \\
$\mathrm{AOD}$ & 0.41 & -0.34 & -0.09 & -0.61 & -0.53 & -0.18 \\
$\mathrm{AOD}_{\text {pol }}$ & 0.65 & 0.03 & 0.64 & -0.25 & 0.23 & 0.07 \\
$\mathrm{AOD}_{\text {pol }} / \mathrm{AOD}$ & 0.74 & 0.06 & 0.68 & -0.16 & -0.05 & 0.13 \\
$\overline{\delta^{\mathrm{V}}}$ & $\mathbf{0 . 8 1}$ & 0.45 & 0.68 & 0.00 & 0.14 & 0.33 \\
$\overline{\delta \mathrm{p}}$ & $\mathbf{0 . 8 1}$ & $\mathbf{0 . 5 7}$ & $\mathbf{0 . 7 2}$ & $\mathbf{0 . 1 5}$ & $\mathbf{0 . 2 6}$ & $\mathbf{0 . 4 0}$ \\
$h_{\text {pol }}$ & 0.54 & -0.42 & 0.46 & -0.59 & -0.59 & -0.22 \\
\hline $09: 00-17: 00 \mathrm{UT}$ & & & & & & \\
\hline & 27 & 28 & 29 & 30 & 31 & $27-31$ \\
\hline $\mathrm{PM}_{10}$ & -0.22 & 0.19 & -0.28 & -0.32 & $\mathbf{0 . 2 2}$ & 0.18 \\
$\mathrm{AOD}$ & -0.23 & -0.24 & 0.41 & -0.88 & -0.58 & -0.13 \\
$\mathrm{AOD}$ & -0.19 & -0.05 & 0.55 & -0.26 & -0.50 & 0.12 \\
$\mathrm{AOD}$ & & & & & \\
\hline$\delta_{\text {pol }} / \mathrm{AOD}$ & -0.09 & -0.03 & 0.58 & -0.03 & -0.46 & 0.18 \\
$\overline{\delta \mathrm{p}}$ & -0.05 & 0.77 & 0.65 & 0.07 & -0.63 & 0.33 \\
$h_{\text {pol }}$ & -0.08 & 0.72 & $\mathbf{0 . 6 8}$ & $\mathbf{0 . 2 3}$ & -0.56 & $\mathbf{0 . 3 7}$ \\
\hline & -0.22 & -0.68 & -0.05 & -0.69 & -0.41 & -0.35 \\
\hline
\end{tabular}

tanus. For each day, the highest positive $r$ values have been stressed in bold font. Independently of the pollen type $\overline{\delta^{p}}$ appears clearly to be the parameter with the highest daily $r$ values. In particular for the total pollen and Platanus the daily $r$ values range between 0.52 and 0.81 on the first 3 days and between 0.12 and 0.26 on the last 2 . Concerning the diurnal $r$ values, the results are not so clear: $\overline{\delta^{\mathrm{p}}}$ still appears as the parameter with the highest $r$ values for Platanus, but no parameter clearly stands out for the total pollen and Pinus.

In the concern to find a possible proxy of the pollen (be it total, Platanus, or Pinus) near-surface concentration with some columnar parameter easily measurable by remote sensing instrument, we examine the correlation between pollen concentration and AOD. The AOD is a columnar parameter which is relatively easily measurable, e.g., with a sun photometer, and which can be retrieved with a relatively high accuracy. For example, in the AERONET (Aerosol Robotic Network; http://aeronet.gsfc.nasa.gov/) worldwide network of sun/sky photometers, the accuracy is \pm 0.02 (Eck et al., 1999). Tables 2, 3, and 4 show that the $r$ values of the AOD parameter, although in majority negative, can frequently change sign and reach values close to zero. The AOD is therefore not an appropriate proxy for the pollen nearsurface concentration. It is interesting to note, en passant, that $\mathrm{AOD}_{\mathrm{pol}} r$ values are not much better and that $\mathrm{AOD}_{\mathrm{pol}}$ would not be a good proxy either. This result emphasizes again that near-surface pollen release and columnar pollen dispersion are not time correlated. The correlation between pollen concentration and $\delta^{\mathrm{V}}$ is also investigated because $\delta^{\mathrm{V}}$ is a lidar product relatively simple to retrieve since it does not require post-acquisition processing. In the case of the MPL system used in this study, $\delta^{\mathrm{V}}$ is obtained by a very simple operation with the two collected powers (see Eq. 3). Although $\overline{\delta^{\mathrm{V}}} r$ values are usually a little lower than $\overline{\delta^{\mathrm{p}}}$ values, the values indicate globally a rather positive correlation between $\overline{\delta^{\mathrm{V}}}$ and the pollen concentration. To investigate further the pros and cons of using $\overline{\delta^{\mathrm{V}}}$ instead of $\overline{\delta^{\mathrm{p}}}$, the retrieval of which is much less straightforward than the retrieval of $\bar{\delta} \mathrm{v}$, we present in Fig. 6 the scatter plots of the daily (00:00-24:00 UT) values of pollen concentration vs. $\overline{\delta^{v}}$ and $\overline{\delta p}$. In this figure the positive slope of the red linear regression line is a clear indicator of the positive correlation between $\overline{\delta^{\mathrm{v}}} / \overline{\delta^{\mathrm{p}}}$ and the pollen concentration. Over the whole event the $\overline{\delta^{\mathrm{p}}}\left(\overline{\delta^{\mathrm{V}}}\right.$; $\left.\overline{\delta^{\mathrm{V}}}-\overline{\delta^{\mathrm{p}}}\right) r$ values are $0.41(0.34 ;-0.07)$ for total pollen, 0.36 $(0.28 ;-0.08)$ for Platanus, and $0.46(0.42 ;-0.04)$ for Pinus. Thus, overall the $\overline{\delta^{\mathrm{V}}} r$ values are between -0.08 and -0.04 smaller than the $\overline{\delta^{\mathrm{p}}}$ ones. The highest $\overline{\delta^{\mathrm{V}}}$ and $\overline{\delta^{\mathrm{p}}} r$ values are reached for Pinus $\left(0.09<\overline{\delta^{\mathrm{V}}} r\right.$ values $<0.70$ and $0.25<\overline{\delta^{\mathrm{p}}}$ $r$ values $<0.68$ ), while the lowest $r$ values are reached for Platanus $\left(0.02<\overline{\delta^{\mathrm{V}}} r\right.$ values $<0.68$ and $0.12<\overline{\delta^{\mathrm{p}}} r$ values $<0.70$ ). One also sees that the days previously classified as days with nocturnal pollen near-surface activity (28, 30 , and 31 March) have the lowest $r$ values. This is mostly due to the points with high concentration and low depolarization ratios visible above the linear regression line, reflecting the nighttime situation of high pollen release without vertical dispersion. For the days classified as days without nocturnal pollen activity the difference between $\overline{\delta^{\mathrm{V}}}$ and $\overline{\delta^{\mathrm{p}}} r$ values are in general smaller than 0.04 , so that it becomes nearly equivalent to use $\overline{\delta^{\mathrm{V}}}$ instead of $\overline{\delta^{\mathrm{p}}}$. For these days the highest $\overline{\delta^{\mathrm{V}}}$ $r$ values are reached for the total pollen. Let us note that the total pollen release and dispersion is especially well correlated on 27 March $\left(\overline{\delta^{\mathrm{V}}}\right.$ and $\overline{\delta^{\mathrm{p}}} r$ values are equal to 0.81). All in all these results suggest the following.

- In all conditions, differences between $\overline{\delta^{\mathrm{V}}}$ and $\overline{\delta^{\mathrm{p}}} r$ values range between 0.08 and 0.04 and $\overline{\delta^{\mathrm{V}}}$ seems to be a proxy better for Pinus and the total pollen concentration than for Platanus concentration.

- Without nocturnal pollen near-surface activity, $\overline{\delta^{\mathrm{V}}}$ and $\overline{\delta \mathrm{p}}$ are nearly equivalent ( $r$ values differences smaller than 0.04 ) and $\overline{\delta^{V}}$ seems to be an appropriate proxy for the total pollen concentration.

It is important to recall that these conclusions have to be taken in a general sense and that, depending on the meteorological conditions, there may be cases for which these statements do not apply. In the following section we seek the possible reasons which could explain the aforementioned correlations between pollen near-surface concentration and columnar depolarization ratios. 


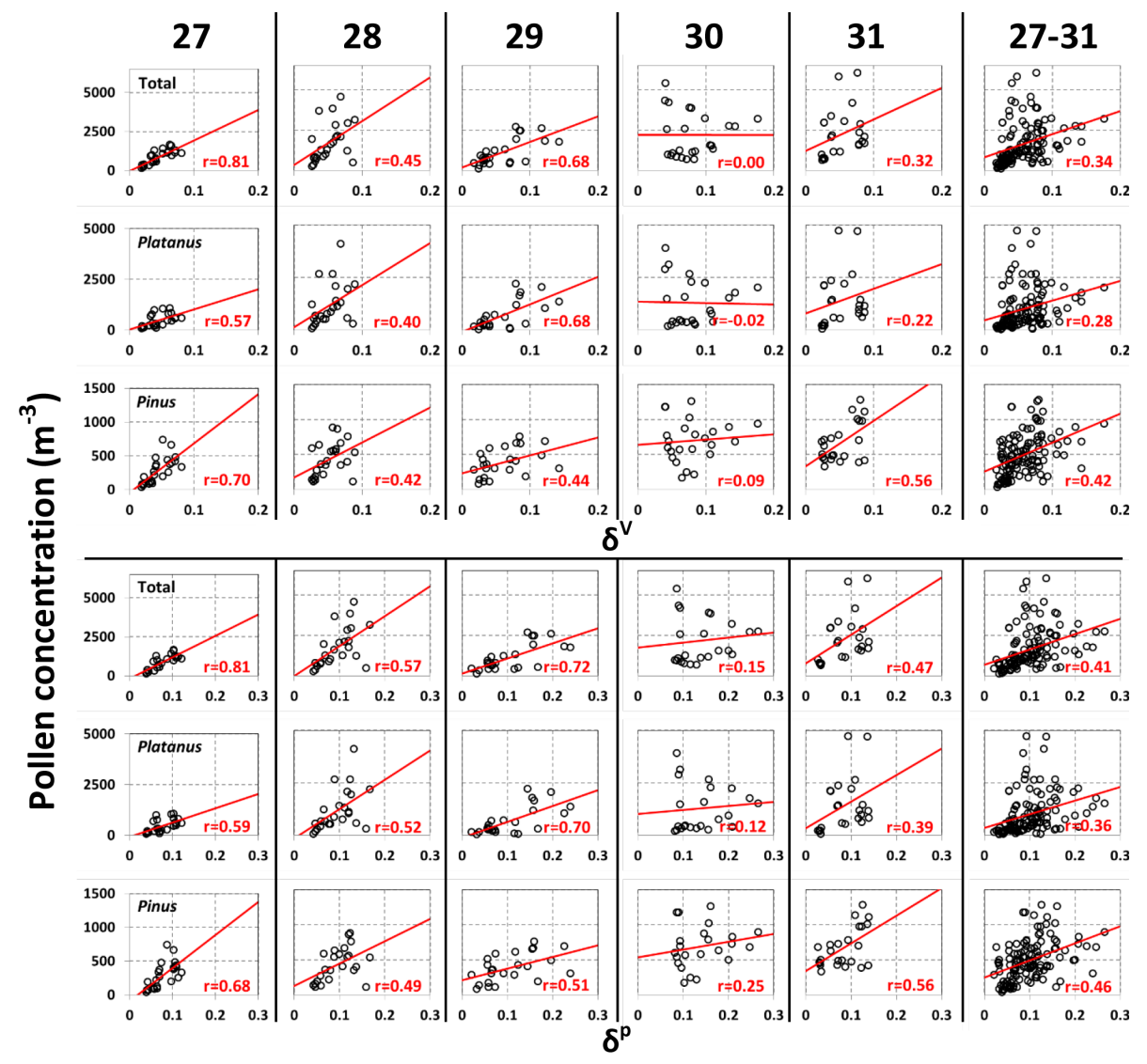

Figure 6. Scatter plot of the pollen concentration (total, Platanus and Pinus) vs. the volume $\left(\overline{\delta^{\mathrm{V}}}\right)$ and the particle $(\overline{\delta \mathrm{p}})$ depolarization ratio integrated in the pollen plume for all 5 days of the pollination event. The linear regression line is in red and the correlation coefficient, $r$, is reported.

Table 3. Idem as Table 2 for Platanus.

\begin{tabular}{lrrrrrr}
\hline 00:00-24:00 UT & & & & & & \\
\hline & 27 & 28 & 29 & 30 & 31 & $27-31$ \\
\hline $\mathrm{PM}_{10}$ & -0.03 & -0.10 & -0.49 & -0.33 & -0.37 & -0.19 \\
$\mathrm{AOD}$ & 0.14 & -0.34 & 0.00 & -0.55 & -0.53 & -0.22 \\
$\mathrm{AOD}_{\text {pol }}$ & 0.36 & -0.03 & 0.63 & -0.23 & -0.32 & 0.01 \\
$\mathrm{AOD}_{\mathrm{pol}} / \mathrm{AOD}$ & 0.44 & -0.01 & 0.65 & -0.15 & -0.15 & 0.07 \\
$\overline{\delta^{\mathrm{V}}}$ & 0.57 & 0.40 & 0.68 & -0.02 & 0.06 & 0.26 \\
$\overline{\delta \mathrm{p}}$ & $\mathbf{0 . 5 9}$ & $\mathbf{0 . 5 2}$ & $\mathbf{0 . 7 0}$ & $\mathbf{0 . 1 2}$ & $\mathbf{0 . 1 9}$ & $\mathbf{0 . 3 4}$ \\
$h_{\text {pol }}$ & 0.22 & -0.44 & 0.36 & -0.55 & -0.64 & -0.29 \\
\hline $09: 00-17: 00 \mathrm{UT}$ & & & & & & \\
\hline & & & & & & \\
\hline $\mathrm{PM}_{10}$ & 27 & 28 & 29 & 30 & 31 & $27-31$ \\
$\mathrm{AOD}_{\mathrm{AOD}}$ & -0.08 & 0.18 & -0.23 & -0.35 & -0.03 & 0.04 \\
$\mathrm{AOD}$ & -0.23 & -0.19 & 0.57 & -0.85 & -0.76 & -0.33 \\
$\overline{\delta_{\mathrm{pol}} \mathrm{V}} / \mathrm{AOD}$ & -0.14 & -0.04 & 0.66 & -0.32 & -0.67 & -0.01 \\
$\overline{\delta \mathrm{p}}$ & -0.03 & -0.04 & 0.66 & -0.11 & -0.62 & 0.12 \\
$h_{\mathrm{pol}}$ & 0.18 & $\mathbf{0 . 7 4}$ & $\mathbf{0 . 7 0}$ & -0.02 & -0.78 & 0.29 \\
\hline & $\mathbf{0 . 3 0}$ & 0.68 & $\mathbf{0 . 7 0}$ & $\mathbf{0 . 1 4}$ & -0.65 & $\mathbf{0 . 3 6}$ \\
& -0.43 & -0.63 & 0.04 & -0.72 & -0.56 & -0.48 \\
\hline
\end{tabular}

\section{Influence of the solar radiation on the pollen vertical transport in the atmosphere}

For the pollen to be dispersed in the atmosphere, vertical transport is needed. According to Mandrioli et al. (1984) the main mechanism driving the vertical movement of atmospheric particles is the atmospheric turbulence. In the ABL atmospheric turbulences result from the vertical movement of air masses due to the heating and cooling of the ground by the sun and to the flow of air (wind) over the ground. At the end of Sect. 3 we showed that the pollen AOD did not present a systematic dependence upon wind speed because of the low wind speeds (usually lower than $3 \mathrm{~m} \mathrm{~s}^{-1}$ ) detected during the pollination event. Thus we examine the possible influence of solar radiations on the vertical transport of pollen thanks to MPL co-located pyranometer solar flux measurements performed at the Barcelona SolRad-Net (Solar Radiation Network, http://solrad-net.gsfc.nasa.gov/) site. The pyranometer is a Kipp and Zonen CMP21 sensor that provides a measurement every 2 min of the total solar flux in the range of 0.3$2.8 \mu \mathrm{m}$. We used SolRad-Net level 1.5 data which have been cleared as free of any operational problems. The solar flux 
Table 4. Idem as Table 2 for Pinus.

\begin{tabular}{lrrrrrr}
\hline 00:00-24:00 UT & & & & & & \\
\hline & 27 & 28 & 29 & 30 & 31 & $27-31$ \\
\hline $\mathrm{PM}_{10}$ & 0.12 & -0.51 & -0.22 & -0.39 & 0.32 & -0.06 \\
$\mathrm{AOD}$ & 0.62 & -0.15 & -0.26 & -0.75 & -0.19 & 0.03 \\
$\mathrm{AOD}_{\text {pol }}$ & 0.76 & 0.27 & 0.43 & -0.29 & 0.36 & 0.29 \\
$\mathrm{AOD}_{\text {pol }} / \mathrm{AOD}$ & $\mathbf{0 . 8 0}$ & 0.27 & 0.55 & -0.17 & $\mathbf{0 . 4 6}$ & 0.29 \\
$\delta_{\mathrm{V}}$ & 0.70 & 0.42 & 0.44 & 0.09 & 0.44 & 0.42 \\
$\overline{\delta \mathrm{p}}$ & 0.68 & $\mathbf{0 . 4 9}$ & 0.51 & $\mathbf{0 . 2 5}$ & 0.45 & $\mathbf{0 . 4 7}$ \\
$h_{\text {pol }}$ & 0.76 & -0.19 & $\mathbf{0 . 6 3}$ & -0.65 & 0.02 & 0.08 \\
\hline $09: 00-17: 00 \mathrm{UT}$ & & & & & & \\
\hline & 27 & 28 & 29 & 30 & 31 & $27-31$ \\
\hline $\mathrm{PM}_{10}$ & -0.16 & $\mathbf{0 . 4 9}$ & -0.21 & -0.14 & $\mathbf{0 . 8 1}$ & $\mathbf{0 . 2 6}$ \\
$\mathrm{AOD}_{\mathrm{AOD}}$ & 0.13 & -0.04 & -0.61 & -0.86 & 0.27 & 0.02 \\
$\mathrm{AOD}$ & 0.00 & 0.14 & -0.43 & -0.04 & 0.32 & 0.15 \\
$\overline{\delta_{\text {pol }}} / \mathrm{AOD}$ & -0.03 & 0.17 & -0.29 & 0.21 & 0.31 & 0.14 \\
$\overline{\delta \mathrm{p}}$ & -0.45 & 0.45 & -0.18 & 0.30 & 0.20 & 0.19 \\
$h_{\text {pol }}$ & -0.79 & 0.38 & -0.07 & $\mathbf{0 . 4 4}$ & 0.10 & 0.22 \\
\hline
\end{tabular}

(also called solar irradiance) measured at ground level is the power per unit area produced by the sun in the form of electromagnetic radiation measured at the Earth's surface after atmospheric absorption and scattering.

Figure 7 shows the solar fluxes as a function of time for all 5 days of the pollination event. On 29 and 30 March clouds alter significantly the diurnal pattern of the solar radiation received at ground level. We have checked on the profiles of the MPL the presence of clouds and their altitude on the 3 clear-sky days. On 27 March, high-level clouds in the range of 9-12 km were present until 09:30 UT, while on 28 March clouds in the range of 8-10 km were present until 10:00 UT and again after 17:00 UT. On 31 March the sky was totally free of clouds with the exception of clouds forming in the ABL from 17:00 UT onwards. The possible influence of the solar radiations on the vertical transport of pollen is examined with the clear-sky days of 27, 28, and 31 March. In the first row of Fig. 8 we represent all together the solar fluxes, $\overline{\delta^{\mathrm{V}}}, \overline{\delta^{\mathrm{p}}}$, and $\mathrm{AOD}_{\mathrm{pol}}$ as a function of time. Every day a diurnal pattern is clearly visible on all curves with an increase in the morning and a decrease in the afternoon. On 27 March the temporal evolution of $\overline{\delta^{\mathrm{v}}}$ and $\overline{\delta^{\mathrm{p}}}$ seems to follow especially well the pattern of the solar flux. In all three cases a time delay is observed between the diurnal evolution of the solar fluxes and the depolarization ratios and of the solar fluxes and $\mathrm{AOD}_{\mathrm{pol}}$. As one could intuitively expect, the pollen vertical transport pattern, triggered by the turbulences caused by the heating/cooling of the ground, should follow with a given time delay (i.e., start after) that of the solar flux. The top plots of Fig. 8 clearly show that the temporal evolution of $\mathrm{AOD}_{\mathrm{pol}}$ is always delayed w.r.t. the solar fluxes. In order to quantify that time delay, $t$, for each day, for each of the two depolarization ratios and for $\mathrm{AOD}_{\mathrm{pol}}$, we have searched the value of $t$ that maximizes the correlation coefficient defined as

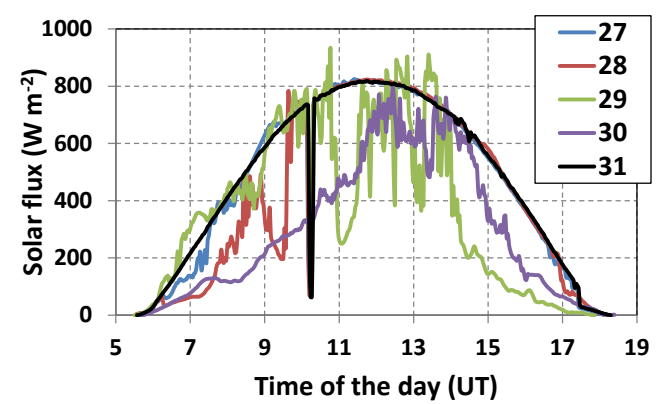

Figure 7. Diurnal cycle for all 5 days of the pollination event of the total downward solar flux measured in the range $0.3-2.8 \mu \mathrm{m}$ at ground level close to the lidar station.

$r(t)=r(F(x), \delta(x-t))$,

where $F$ is the solar flux and $\delta$ is either $\overline{\delta^{\mathrm{v}}}, \overline{\delta^{\mathrm{p}}}$, or $\mathrm{AOD}_{\mathrm{pol}}$. The optimized value of $t$ that maximizes the correlation coefficient is called $t_{\mathrm{opt}}$. The second, third, and fourth rows of Fig. 8 present the scatter plots of the solar flux vs. $\overline{\delta^{\mathrm{v}}}, \overline{\delta^{p}}$, and $\mathrm{AOD}_{\mathrm{pol}}$, respectively. We have represented the scatter plots without time delay (red color, $r(t=0)$ ) and the scatter plots with a time delay equal to $t_{\text {opt }}$ (blue color, $r\left(t=t_{\text {opt }}\right)$ ). The $\overline{\delta^{\mathrm{V}}} r$ values without time delay are in the range of 0.490.86 , which already indicates a good correlation between the solar flux and $\overline{\delta^{\mathrm{V}}}$. The $r$ values for $t=t_{\mathrm{opt}}$ are significantly better as they range from 0.90 to 0.95 . On 27 and 31 March $t_{\mathrm{opt}}=-1$ and $-2 \mathrm{~h}$, respectively, which indicates that the diurnal pattern of $\overline{\delta^{\mathrm{V}}}$ follows that of the solar flux delayed 1 and $2 \mathrm{~h}$. On 28 March $t_{\mathrm{opt}}=+1 \mathrm{~h}$, which indicates that the diurnal pattern of $\overline{\delta^{\mathrm{V}}}$ is ahead of that of the solar flux approximately $1 \mathrm{~h}$. Let us recall that 28 March is one of the days with nocturnal pollen near-surface activity and with the highest wind speeds. The maximum observed at 09:00 UT is due to a low layer of pollen $(<0.5 \mathrm{~km})$ with relatively high values of $\delta^{\mathrm{V}}$ (see Fig. 3b). As far as $\overline{\delta^{\mathrm{p}}}$ is concerned, the $r$ values without time delay $\left(0.45<\overline{\delta^{\mathrm{p}}} r(t=0)\right.$ values $\left.<0.89\right)$ are also significantly improved when an optimized time delay is applied $\left(0.80<\overline{\delta \mathrm{p}} r\left(t=t_{\text {opt }}\right)\right.$ values $\left.<0.91\right)$. The optimized value of $t$ for $\overline{\delta^{\mathrm{p}}}$ are the same than for $\overline{\delta^{\mathrm{V}}}$ (except on 27 March when $t_{\mathrm{opt}}=0$ for $\overline{\delta^{\mathrm{p}}}$ ). After the optimized time delay is applied, $\overline{\delta^{\mathrm{V}}} r$ values are all greater or equal to the $\overline{\delta^{\mathrm{p}}} r$ values. Differences vary between +0.03 and +0.08 . These findings indicate that $\overline{\delta^{\mathrm{V}}}$ is better correlated to the solar flux than $\overline{\delta^{\mathrm{p}}}$ is. This happens probably because $\delta^{\mathrm{V}}$ retrieval is much more straightforward than $\delta^{\mathrm{p}}$ retrieval and thus its uncertainty is smaller. For $\mathrm{AOD}_{\text {pol }}$, the $r$ values without time delay $\left(0.37<\mathrm{AOD}_{\mathrm{pol}} r(t=0)\right.$ values $\left.<0.84\right)$ are lower than the ones of the depolarization ratios, but they become higher when an optimized time delay is applied $\left(0.91<\mathrm{AOD}_{\text {pol }}\right.$ $r\left(t=t_{\mathrm{opt}}\right)$ values $\left.<0.98\right)$. The optimized time delays are all 

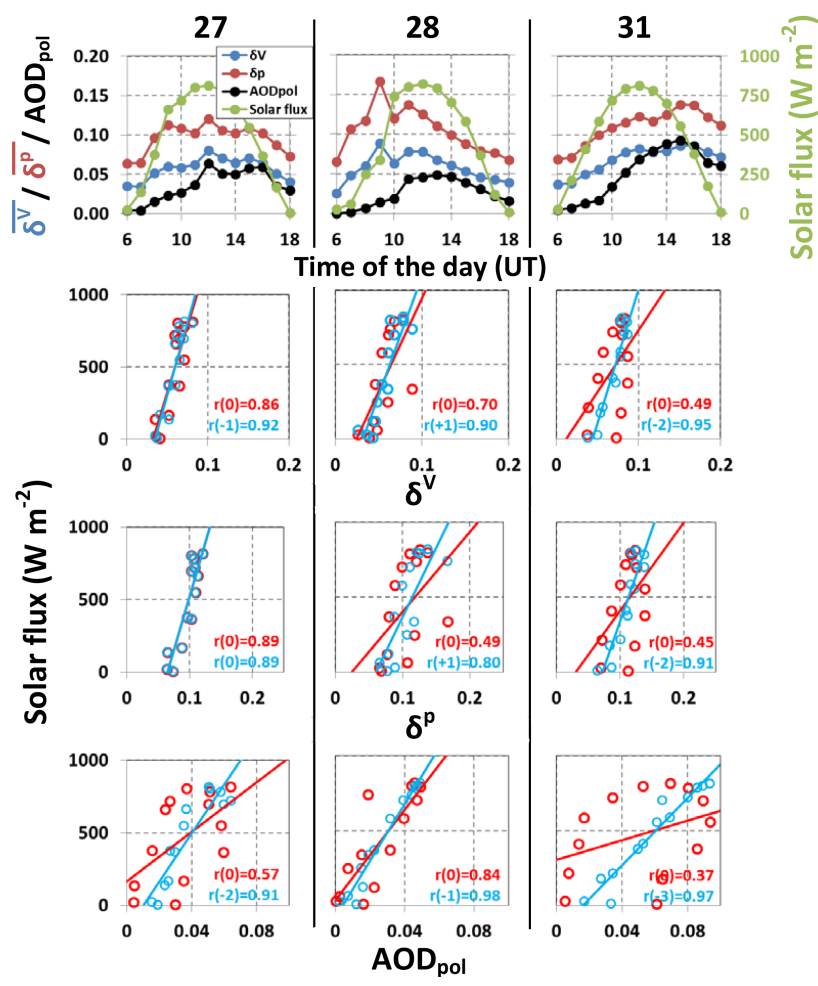

Figure 8. (top) Diurnal evolution of $\overline{\delta^{\mathrm{V}}}, \overline{\delta \mathrm{p}}, \mathrm{AOD}_{\text {pol }}$, and solar fluxes on 27, 28, and 31 March between 06:00 and 18:00 UT; (center/top) scatter plot of the solar flux vs. $\overline{\delta^{\mathrm{V}}}$; (center/bottom) scatter plot of the solar flux vs. $\overline{\delta \mathrm{p}}$; (bottom) scatter plot of the solar flux vs. $\mathrm{AOD}_{\mathrm{pol}}$. In each scatter plot, straight lines are linear regression lines; the red color corresponds to $t=0$; the blue color corresponds to $t=t_{\text {opt }}$. The values of $r(t)$ are reported in each scatter plot.

negative, as foreseen from the top plot of Fig. 8 and vary between -1 and $-3 \mathrm{~h}$. Among the three parameters studied $\left(\overline{\delta^{\mathrm{V}}}, \overline{\delta^{\mathrm{p}}}\right.$, and $\left.\mathrm{AOD}_{\mathrm{pol}}\right), \mathrm{AOD}_{\mathrm{pol}}$ presents the highest correlation with the solar radiation reaching the ground. The most probable explanation of this finding is that $\mathrm{AOD}_{\text {pol }}$ is a measure intrinsic to pollen, while $\overline{\delta^{\mathrm{V}}}$ and $\overline{\delta^{\mathrm{p}}}$ depend partly on the mixing of pollen with local aerosols.

\section{Conclusion}

For the first time near-surface and columnar measurements of airborne pollen have been performed continuously at a temporal resolution of $1 \mathrm{~h}$ during a 5-day pollination event in a large European city. At the peak of the event 2830 pollen and fungal spore grains were counted per cubic meter per day. Platanus and Pinus pollen types represented together more than $80 \%$ of the total concentration. Hourly concentration maxima of 4700 and $1200 \mathrm{~m}^{-3}$ were found for Platanus and Pinus, respectively. Except on one day, the total pollen concentration at ground level followed a clear diurnal cycle and was correlated positively with temperature $(r=0.95)$ and wind speed $(r=0.82)$ but negatively with relative humidity $(r=-0.18)$. These results indicate a strong dependence of pollen release upon the meteorological conditions, especially temperature and wind speed. As far as pollen AOD is concerned, its peaks were systematically associated with minima of relative humidity and maxima of temperature but they did not present a systematic dependence upon wind speed.

The pollen AOD showed a clear diurnal cycle with maxima between 12:00 and 15:00 UT. The diurnal (09:0017:00 UT) mean of $\mathrm{AOD}_{\text {pol }}$ was 0.05 over the whole event and represented $29 \%$ of the total AOD. However, peaks of $\mathrm{AOD}_{\text {pol }}$ and $\mathrm{AOD}_{\mathrm{pol}} / \mathrm{AOD}$ of, respectively, 0.12 and $78 \%$ were found in the hourly data. The diurnal mean volume and particle depolarization ratios in the pollen plume were 0.08 and 0.14 , with hourly maxima of 0.18 and 0.33 , respectively. The diurnal height of the pollen plume was found at $1.24 \mathrm{~km}$ on average with maxima varying in the range of $1.47-1.78 \mathrm{~km}$.

We have investigated the possible correlations between pollen near-surface concentration and columnar properties. Between concentration and AOD (be it total or pollen AOD) the correlation was rather poor, which emphasizes that nearsurface pollen release and columnar pollen dispersion are not time correlated. $\overline{\delta^{\mathrm{V}}}$ and $\overline{\delta^{\mathrm{p}}}$ were positively correlated with the total pollen concentration. The daily mean $\overline{\delta^{\mathrm{V}}}$ and $\overline{\delta^{\mathrm{p}}} r$ values were, respectively, 0.34 and 0.41 , with maxima of 0.81 reached on the first day of the event for both parameters. When we remove the days with nocturnal pollen near-surface activity, $\overline{\delta^{\mathrm{V}}}$ and $\overline{\delta^{\mathrm{p}}} r$ values were greater than 0.68 and their difference smaller than $0.04 . \overline{\delta^{\mathrm{V}}}$, and a fortiori $\overline{\delta^{\mathrm{p}}}$ appeared to be an appropriate proxy for the total pollen concentration, especially when no pollen nocturnal activity is recorded.

The possible influence of solar radiations, which cause the atmospheric turbulences responsible for the aerosol vertical motion, on the vertical transport of pollen was examined by means of $\overline{\delta^{\mathrm{V}}}, \overline{\delta^{\mathrm{p}}}, \mathrm{AOD}_{\mathrm{pol}}$, and solar fluxes measured during the 3 clear-sky days of the pollination event. Correlation coefficients better than $0.49(0.45 ; 0.37)$ were obtained for $\overline{\delta^{\mathrm{V}}}$ $\left(\overline{\delta \mathrm{p}} ; \mathrm{AOD}_{\mathrm{pol}}\right)$ vs. solar flux. In all cases we could find a time delay between the pattern of the pollen vertical transport and the one of the solar flux that could maximize the $r$ values. After the optimized time delay was applied, correlation coefficients better than $0.90(0.80 ; 0.91)$ were obtained for $\overline{\delta^{\mathrm{V}}}$ $\left(\overline{\delta \mathrm{p}} ; \mathrm{AOD}_{\mathrm{pol}}\right)$ vs. solar flux. This study demonstrates that, in the absence of other depolarizing particles, the volume depolarization ratio is an excellent tool to track airborne pollen grains. On the one hand, it is relatively well correlated with the pollen near-surface concentration which quantifies the pollen release; on the other hand, it is very well correlated with the solar fluxes on which the pollen vertical dispersion depends.

In our opinion this work puts forward two potential perspectives. First, relatively simple polarization-sensitive lidar systems (with at least two channels) able to produce contin- 
uously profiles of the volume depolarization ratio are very attractive tools for modellers to validate their pollen concentration forecasting models and/or perform data assimilation. The question was raised for $\mathrm{PM}_{10}$ concentration by Wang et al. (2013). Second, the fact that large grains of pollen (of diameter ranging roughly $20-70 \mu \mathrm{m}$ ) are capable of producing AOD of 0.12 raises the question of their effect in terms of radiative forcing. Otto et al. (2011) demonstrated that large mineral dust particles with a diameter of $50 \mu \mathrm{m}$ produced a radiative forcing at the surface almost 4 times greater than the one produced by particles with a diameter of $5 \mu \mathrm{m}$. Large pollen grains may behave the same. Further research on that subject is definitely necessary.

Acknowledgements. Lidar data analysis was supported by the ACTRIS (Aerosols, Clouds, and Trace Gases Research Infrastructure Network) Research Infrastructure Project funded by the European Union's Horizon 2020 research and innovation programme under grant agreement no. 654169 and previously under grant agreement no. 262254 in the Seventh Framework Programme (FP7/20072013), by the Spanish Ministry of Economy and Competitiveness (projects TEC2012-34575 and TEC2015-63832-P) and of Science and Innovation (project UNPC10-4E-442) and EFRD (European Fund for Regional Development), and by the Department of Economy and Knowledge of the Catalan autonomous government (grant 2014 SGR 583). The authors also thank Xavier Lleberia and Marc Rico from the Agència de Salut Pública de l'Ajuntament de Barcelona for providing the $\mathrm{PM}_{10}$ measurements, and the Facultad de Física of the Universitat de Barcelona for providing the meteorological measurements. Andrés Alastuey and Cristina Reche from the Instituto de Diagnóstico Ambiental y Estudios del Agua/Consejo Superior de Investigaciones Científicas (IDÆA/CSIC) are thanked for their useful advice about the $\mathrm{PM}_{10}$ measurements.

Edited by: J. Huang

\section{References}

Alba, F., Díaz de la Guardia, C., and Comtois, P.: The effect of meteorological parameters on diurnal patterns of airborne olive pollen concentration, Grana, 39, 200-208, 2000.

Bartková-Šcevková, J.: The influence of temperature, relative humidity and rainfall on the occurrence of pollen allergens (Betula, Poaceae, Ambrosia artemisiifolia) in the atmosphere of Bratislava (Slovakia), Int. J. Biometeorol., 48, 1-5, 2003.

Behrendt, A. and Nakamura, T.: Calculation of the calibration constant of polarization lidar and its dependency on atmospheric temperature, Optics Express, 10, 805-817, 2002.

Belmonte, J. and Roure, J. M.: Characteristics of the aeropollen dynamics at several localities in Spain, Grana, 30, 361-372, 1991.

Belmonte, J., Canela, M., Guàrdia, R., Guàrdia, R. A., Sbai, L., Vendrell, M., Cariñanos, P., Díaz de la Guardia, C., Dopazo, A., Fernández, D., Gutiérrez, M., and Trigo, M. M.: Aerobiological dynamics of the Cupressaceae pollen in Spain, 1992-98, Polen, 10, 27-38, 1999.
Boers, R., Spinhirne, J. D., and Hart, W. D.: Lidar Observations of the Fine-Scale Variability of Marine Stratocumulus Clouds, J. Appl. Meteorol., 27, 797-810, 1988.

Burch, M. and Levetin, E.: Effects of meteorological conditions on spore plumes, Int. J. Biometeorol., 46, 107-117, 2002.

Burge, H. A. and Rogers, C. A.: Outdoor allergens, Environ. Health Perspect., 108, 653-659, 2000.

Campbell, J. R., Hlavka, D. L., Welton, E. J., Flynn, C. J., Turner, D. D., Spinhirne, J. D., Scott, V. S., and Hwang, I. H.: Full-time, eye-safe cloud and aerosol lidar observation at Atmospheric Radiation Measurement Program sites: instruments and data processing, J. Atmos. Ocean. Tech., 19, 431-442, 2002.

Cao, X., Roy, G., and Bernier, R.: Lidar polarization discrimination of bioaerosols, Opt. Eng., 49, 76720P, doi:10.1117/12.849649, 2010.

Cecchi, L.: From pollen count to pollen potency: the molecular era of aerobiology, Eur. Respir. J., 42, 898-900, doi:10.1183/09031936.00096413, 2013.

Dahl, A., Galán, C., Hajkova, L., Pauling, A., Sikoparija, B., Smith, M., and Vokou, D.: The Onset, Course and Intensity of the Pollen Season, in: Allergenic Pollen. A review of the Production, Release, Distribution and Health Impacts, edited by: Sofiev, M. and Bergmann, K.-Ch., 29-70, doi:10.1007/978-94-007-4881-1, Springer, 2013.

De Linares, C., Postigo, I., Belmonte, J., Canela, M., and Martínez, J.: Optimization of the measurement of outdoor airborne allergens using a protein microarrays platform, Aerobiologia, 30, 217-227, doi:10.1007/s10453-013-9322-2, 2014.

Denning, D. W., O’Driscoll, B. R., Hogaboam, C. M., Bowyer, P., and Niven, R.M.: The link between fungi and severe asthma: a summary of the evidence, Eur. Respir. J., 27, 615-626, 2006.

Díaz de la Guardia, C., Sabariego, S., Alba, F., Ruiz, L., García Mozo, H., Toro Gil, F. J., Valencia, R., Rodríguez Rajo, F. J., Guàrdia, A., and Cervigón, P.: Aeropalynological study of the genus Platanus L. in the Iberian Peninsula, Polen, 10, 89-97, 1999.

Eck, T. F., Holben, B. N., Reid, J. S., Dubovik, O., Kinne, S., Smirnov, A., O'Neill, N. T., and Slutsker, I.: The wavelength dependence of the optical depth of biomass burning, urban and desert dust aerosols, J. Geophys. Res., 104, 31333-31349, 1999.

Fernald, F. G.: Analysis of atmospheric lidar observations: some comments, Appl. Optics, 23, 652-653, 1984.

Flynn, C. J., Mendoza, A., Zheng, Y., and Mathur, S.: Novel polarization-sensitive micropulse lidar measurement technique, Opt. Express, 15, 2785-2790, 2007.

Freudenthaler, V., Esselborn, M., Wiegner, M., Heese, B., Tesche, M., Ansmann, A., Muller, D., Althausen, D., Wirth, M., Fix, A., Ehret, G., Knippertz, P., Toledano, C., Gasteiger, J., Garhammar, M., and Seefeldner, M.: Depolarizationratio profiling at several wavelengths in pure Saharan dust during SAMUM 2006, Tellus B, 61, 165-179, doi:10.1111/j.1600-0889.2008.00396.x, 2009.

Gabarra, E., Belmonte, J., and Canela, M.: Aerobiological behaviour of Platanus L. pollen in Catalonia (North-East Spain), Aerobiologia, 18, 185-193, 2002.

Galán Soldevilla, C., Cariñanos González, P., Alcázar Teno, P., and Domínguez Vilches, E.: Manual de Calidad y Gestión de la Red Española de Aerobiología, Servicio de Publicaciones, Universidad de Córdoba, 2007. 
Gimmestad, G. G.: Reexamination of depolarization in lidar measurements, Appl. Optics, 47, 3795-3802, 2008.

Grinn-Gofrón, A. and Strzelczak, A.: Artificial neural network models of relationships between Cladosporium spores and meteorological factors in Szczecin (Poland), Grana, 47, 305-315, 2008.

Hart, M., Wentworth, J., and Bailey, J.: The effects of trap height and weather variables on recorded pollen concentration at Leicester, Grana, 33, 100-103, 1994.

Hirst, J. M.: An automatic volumetric spore trap, Ann. Appl. Biol., 39, 257-265, 1952.

Huang, Z., Huang, J., Bi, J., Wang, G., Wang, W., Fu, Q., Li, Z., Tsay, S.-C., and Shi, J.: Dust aerosol vertical structure measurements using three MPL lidars during 2008 China-U.S. joint dust field experiment, J. Geophys. Res., 115, D00K15, doi:10.1029/2009JD013273, 2010.

Infante, F., Castro, A., Domínguez, E., Guárdia, A., Méndez, J., Sabariego, S., and Vega, A.: A comparative study of the incidence of Cladosporium conidia in the atmosphere of five Spanish cities, Polen, 10, 15-23, 1999.

Jato, M., Rodríguez, F., and Seijo, M.: Pinus pollen in the atmosphere of Vigo and its relationship to meteorological factors, Int. J. Biometeorol., 43, 147-153, 2000.

Karatzas, K.D., Riga, M., and Smith, M.: Presentation and Dissemination of Pollen Information, in: Allergenic Pollen. A review of the Production, Release, Distribution and Health Impacts, edited by: Sofiev, M. and Bergmann, K.-Ch., 217-247, doi:10.1007/978-94-007-4881-1, Springer, 2013.

Klett, J. D.: Lidar inversion with variable backscatter / extinction ratios, Appl. Optics, 24, 1638-1643, 1985.

Lacey, J.: The aerobiology of conidial fungi, Biology of Conidial Fungi, 1, 373-416, 1981

Landulfo, E., Papayannis, A., Artaxo, P., Castanho, A. D. A., de Freitas, A. Z., Souza, R. F., Vieira Junior, N. D., Jorge, M. P. M. P., Sánchez-Ccoyllo, O. R., and Moreira, D. S.: Synergetic measurements of aerosols over São Paulo, Brazil using LIDAR, sunphotometer and satellite data during the dry season, Atmos. Chem. Phys., 3, 1523-1539, doi:10.5194/acp-3-1523-2003, 2003.

Latorre, F. and Caccavari, M. A.: Airborne pollen patterns in Mar del Plata atmosphere (Argentina) and its relationship with meteorological conditions, Aerobiologia, 25, 297-312, doi:10.1007/s10453-009-9134-6, 2009.

Lopez, M. and Salvaggio, J. E.: Mold-sensitive asthma, Clin. Rev. Allerg., 3, 183-196, 1985.

Mandrioli, P., Negrini, M. G., Cesari, G., and Morgan, G.: Evidence for long range transport of biological and anthropogenic aerosol particles in the atmosphere, Grana, 23, 43-53, 1984.

McCartney, H. A.: Dispersal of spores and pollen from crops, Grana, 33, 76-80, doi:10.1080/00173139409427835, 1994.

Melfi, S. H., Spinhirne, J. D., Chou, S. H., and Palm, S. P.: Lidar Observation of the Vertically Organized Convection in the Planetary Boundary Layer Over the Ocean, J. Clim. Appl. Meteorol., 24, 806-821, 1985.

Noh, Y. M., Müller, D., Lee, H. L., and Choi, T. J.: Influence of biogenic pollen on optical properties of atmospheric aerosols observed by lidar over Gwangju, South Korea, Atmos. Environ., 69, 139-147, doi:10.1016/j.atmosenv.2012.12.018, 2013a.

Noh, Y. M., Lee, H., Mueller, D., Lee, K., Shin, D., Shin, S., Choi, T. J., Choi, Y. J., and Kim, K. R.: Investigation of the diurnal pattern of the vertical distribution of pollen in the lower troposphere using LIDAR, Atmos. Chem. Phys., 13, 7619-7629, doi:10.5194/acp-13-7619-2013, 2013b.

Otto, S., Trautmann, T., and Wendisch, M.: On realistic size equivalence and shape of spheroidal Saharan mineral dust particles applied in solar and thermal radiative transfer calculations, Atmos. Chem. Phys., 11, 4469-4490, doi:10.5194/acp-11-44692011, 2011.

Pakpour, S., Li, D. W., and Klironomos, J.: Relationships of fungal spore concentrations in the air and meteorological factors, Fungal Ecol., 13, 130-134, 2015.

Puiggròs, A., Muñoz-Cano, R., Roger Reig, A., Raga, E., Belmonte, J., and Valero, A.: Prevalence of Sensitization to Pollen From Trees Planted in Barcelona City, J. Investig. Allergol. Clin. Immunol., 25, 133-162, 2015.

Querol, X., Alastuey, A., Rodríguez, S., Plana, F., Ruiz, C. R., Cots, N., Massagué, G., and Puig, O.: $\mathrm{PM}_{10}$ and $\mathrm{PM}_{2.5}$ source apportionment in the Barcelona metropolitan area, Catalonia, Spain, Atmos. Environ., 35, 6407-6419, 2001.

Raynor, G. S., Ogden, E. C., and Hayes, J. V.: Variation in ragweed pollen concentration to a height of 108 meters, J. Allergy Clinical Immun., 51, 199-207, 1973.

Reba, M. N. M., Rocadenbosch, F., Sicard, M., Kumar, D., and Tomás, S.: On the lidar ratio estimation from the synergy between AERONET sun-photometer data and elastic lidar inversion, Proc. of the 25th International Laser Radar Conference, vol. 2, ISBN 978-5-94458-109-9, Saint-Petersburg (Rusia), 5-9 July 2010, 1102-1105, 2010.

Roy, G., Cao, X., and Bernier, R.: On the information content of linear and circular depolarization signatures of bioaerosols, Proc. of SPIE Chemical, Biological, Radiological, Nuclear, and Explosives (CBRNE) Sensing XII, edited by: Fountain, A. W. and Gardner, P. J., Proc. of SPIE Vol. 8018, 801807, doi:10.1117/12.883713, 2011.

Sasano, Y. and Nakane, H.: Significance of the extinction/backscatter ratio and the boundary value term in the solution for the two-component lidar equation, Appl. Optics, 23, 11-13, 1984.

Sassen, K.: Boreal tree pollen sensed by polarization lidar: depolarizing biogenic chaff, Geophys. Res. Lett., 35, L18810, doi:10.1029/2008GL035085, 2008.

Scheifinger, H., Belmonte, J., Buters, J., Celenk, S., Damialis, A., Dechamp, Ch., García-Mozo, H., Gehrig, R., Grewling, L., Halley, J. M., Hogda, K.-A., Jäger, S., Karatzas, K., Karlsen, S.-R., Koch, E., Pauling, A., Peel, R., Sikoparija, B., Smith, M., GalánSoldevilla, C., Thibaudon, M., Vokou, D., and de Weger, L. A.: Monitoring, Modeling and forecasting of the Pollen Season, in: Allergenic Pollen. A review of the Production, Release, Distribution and Health Impacts, edited by: Sofiev, M. and Bergmann, K.Ch., 127-158, doi:10.1007/978-94-007-4881-1, Springer, 2013.

Shimizu, A., Sugimoto, N., Matsui, I., Arao, K., Uno, I., Murayama, T., Kagawa, N., Aoki, K., Uchiyama, A., and Yamazaki, A.: Continuous observations of Asian dust and other aerosols by polarization lidars in China and Japan during ACE-Asia, J. Geophys. Res., 109, D19S17, doi:10.1029/2002JD003253, 2004.

Sicard, M., Pérez, C., Rocadenbosch, F., Baldasano, J. M., and García-Vizcaino, D.: Mixed-layer depth determination in the Barcelona coastal area from regular lidar measurements: meth- 
ods, results and limitations, Bound.-Lay. Meteorol., 119, 135$157,2006$.

Sicard, M., Rocadenbosch, F., Reba, M. N. M., Comerón, A., Tomás, S., García-Vízcaino, D., Batet, O., Barrios, R., Kumar, D., and Baldasano, J. M.: Seasonal variability of aerosol optical properties observed by means of a Raman lidar at an EARLINET site over Northeastern Spain, Atmos. Chem. Phys., 11, 175-190, doi:10.5194/acp-11-175-2011, 2011.

Simon-Nobbe, B., Denk, U., Pöll, V., Rid, R., and Breitenbach, M.: The spectrum of fungal allergy, Int. Arch. Allergy Immunol., 145, 58-86, 2008.

Skjøth, C. A., Sikoparija, B., and Jäger, S.: Pollen sources, in: Allergenic Pollen. A review of the Production, Release, Distribution and Health Impacts, edited by: Sofiev, M. and Bergmann, K.-Ch., 9-27, doi:10.1007/978-94-007-4881-1, Springer, 2013.

Skjøth, C. A., Damialis, A., Belmonte, J., De Linares, C., Fernández-Rodríguez, S., Grinn-Gofroń, A., Jędryczka, M., Kasprzyk, I., Magyar, D., Myszkowska, D., Oliver, G., Páldy, A., Pashley, C. H., Rasmussen, K., Satchwell, J., Thibaudon, M., Tormo-Molina, R., Vokou, D., Ziemianin, M., and Werner, M.: Alternaria spores in the air across Europe: abundance, seasonality and relationships with climate, meteorology and local environment, Aerobiologia, 32, 3-22, doi:10.1007/s10453-0169426-6, 2016

Sofiev, M., Belmonte, J., Gehrig, R., Izquierdo, R., Smith, M., Dahl, A., and Siljamo, P.: Airborne Pollen Transport, in: Allergenic Pollen. A review of the Production, Release, Distribution and Health Impacts, edited by: Sofiev, M. and Bergmann, K.-Ch., 127-158, doi:10.1007/978-94-007-4881-1, Springer, 2013.
Spinhirne, J. D.: Micro pulse lidar, IEEE T. Geosci. Remote Sens., 31, 48-55, 1993.

Sugimoto, N., Huang, Z., Nishizawa, Y., Matsui, I., and Tatarov, B.: Fluorescence from atmospheric aerosols observed with a multichannel lidar spectrometer, Opt. Express, 20, 20800-20807, doi:10.1364/OE.20.020800, 2012.

Vázquez, L., Galán, C., and Domínguez-Vilches, E.: Influence of meteorological parameters on olea pollen concentrations in Córdoba (South-western Spain), Int. J. Biometeorol., 48, 83-90, 2003.

Wang, Y., Sartelet, K. N., Bocquet, M., and Chazette, P.: Assimilation of ground versus lidar observations for $\mathrm{PM}_{10}$ forecasting, Atmos. Chem. Phys., 13, 269-283, doi:10.5194/acp-13-2692013, 2013.

WHO: World Health Report 2003: A Vision for Global Health, Shaping the Future, World Health Organization, 2003.

Weikl, F., Radl, V., Munch, J. C., and Pristch, K.: Targeting allergenic fungi in agricultural environments aids the identification of major sources and potential risks for human health, Sci. Total Environ., 529, 223-230, 2015.

Wodehouse, R. P.: Pollen grains, McGraw-Hill, New York, 1935. 